Data rescue-collection of precious and laborious in situ observed data

\title{
Large-scale ecological field data for satellite validation in deciduous forests and grasslands
}

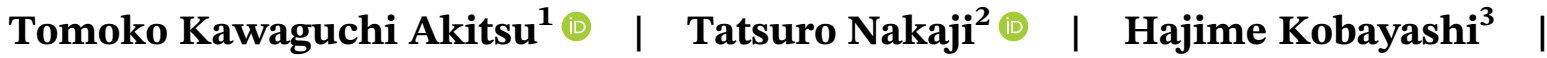 \\ Tetsuo Okano $^{3}$ | Yoshiaki Honda ${ }^{4}$ | Undrakh Bayarsaikhan ${ }^{5}$ | Terigele ${ }^{5}$ | \\ Masato Hayashi $^{6}$ ｜ Tsutom Hiura $^{7}$ ｜ Reiko Ide $^{8}$ | Susumu Igarashi ${ }^{9}$ | \\ Koji Kajiwara $^{4}$ ｜ Syoji Kumikawa $^{9}$ ｜ Yuuichi Matsuoka ${ }^{9}$ | Takashi Nakano ${ }^{10}$ \\ Tomoko Nakano $^{11}$ | Atsushi Okuda ${ }^{9}$ | Tomoaki Sato' ${ }^{9}$ Kaoru Tachiiri ${ }^{12}$ |

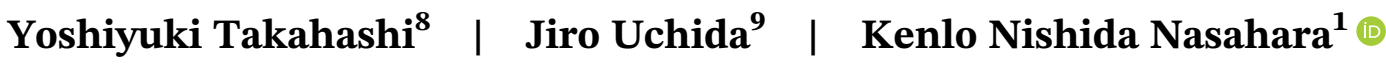 \\ ${ }^{1}$ Faculty of Life and Environmental Sciences, University of Tsukuba, Tsukuba, Japan \\ ${ }^{2}$ Uryu Experimental Forest, Field Science Center for Northern Biosphere, Hokkaido University, Horokanai, Japan \\ ${ }^{3}$ Faculty of Agriculture, Shinshu University, Minami Minowa, Japan \\ ${ }^{4}$ Center for Environmental Remote Sensing, Chiba University, Chiba, Japan \\ ${ }^{5}$ Graduate School of Life and Environmental Science, University of Tsukuba, Tsukuba, Japan \\ ${ }^{6}$ Earth Observation Research Center, Japan Aerospace Exploration Agency, Tokyo, Japan \\ ${ }^{7}$ Graduate School of Agricultural and Life Sciences, The University of Tokyo, Tokyo, Japan \\ ${ }^{8}$ Center for Global Environmental Research, National Institute for Environmental Studies, Tsukuba, Japan \\ ${ }^{9}$ Tomakomai Experimental Forest, Field Science Center for Northern Biosphere, Hokkaido University, Tomakomai, Japan \\ ${ }^{10}$ Mount Fuji Research Institute, Fujiyoshida, Japan \\ ${ }^{11}$ Faculty of Economics, Chuo University, Hachioji, Japan \\ ${ }^{12}$ Research Institute for Global Change, Japan Agency for Marine-Earth Science and Technology, Yokohama, Japan
}

\section{Correspondence}

Tomoko Kawaguchi Akitsu, Faculty of Life and Environmental Sciences,

University of Tsukuba, 1-1-1, Tennodai, Tsukuba 305-8572, Japan.

Email: tomo.akki878@gmail.com

Funding information

Japan Aerospace Exploration Agency, Grant/Award Number: ER2GCF103; Japan Aerospace Exploration Agency, Grant/Award Number: 116

\section{Abstract}

In situ accurate data sets of leaf area index (LAI), above-ground biomass (AGB), and fraction of absorbed photosynthetically active radiation (fAPAR) are indispensable to validate and improve ecological products obtained from satellites. In situ data for satellite validation must be created not from a singlepoint data but from areal data (such as multiple-points data) representing a satellite footprint. Using multiple-points data, the error of in situ data can be calculated statistically. The quantification of the error in the in situ data enables us to evaluate the discrepancy between the satellites' products and the in situ data as the error in the in situ data and the estimation error in the products separately. Besides, the accuracy of the in situ data is required to be much higher than the accuracy of the satellite products which was officially set. To obtain such in situ data, we have established observation sites for typical land cover types in East Asia, from temperate to cool ecosystems: deciduous needleleaved forest (DNF), evergreen needle-leaved forest (ENF), deciduous broadleaved forest $(\mathrm{DBF})$, and grassland (GL). We conducted the observations in $500 \mathrm{~m} \times 500 \mathrm{~m}$ areas, which is the footprint scale of the Global Change 
Observation Mission-Climate satellite. In this paper, the data of LAI, AGB, and fAPAR observed at DNF, DBF, and GL (i.e., except at ENF) are reported. These data are useful even for the validation of other satellite products, especially with higher spatial resolution. Also, the long-term tree census data from 2005 to 2018 at DNF are reported.

The complete data set for this abstract published in the Data Paper section of the journal is available in electronic format in MetaCat in JaLTER at http://db. cger.nies.go.jp/JaLTER/metacat/metacat/ERDP-2020-16.1/jalter-en.

\section{K E Y W O R D S}

above-ground biomass, fAPAR, leaf area index, long-term tree census data, satellite validation data set

\section{1 | INTRODUCTION}

Validation by in situ data is essential for satellite remote sensing of ecosystems. However, it is not easy to obtain in situ data for satellite validation (e.g., Cohen et al., 2006; Fuster et al., 2020; Morisette et al., 2006; Wang et al., 2004). It is because the spatial resolution (i.e., pixel size) of satellite products, especially taken by global sensors such as the Moderate Resolution Imaging Spectroradiometer, is sometimes too high (such as $500 \mathrm{~m} \times 500 \mathrm{~m}$ or $250 \mathrm{~m} \times 250 \mathrm{~m}$ ) to conduct the in situ observation. It is especially true for ecological variables such as leaf area index (LAI), above-ground biomass (AGB), and fraction of absorbed photosynthetically active radiation (fAPAR), because of their spatial heterogeneity and microtopography. To challenge this issue, a project called "JAXA super sites 500" was initiated to make in situ observations of these variables covering areas of $500 \mathrm{~m} \times 500 \mathrm{~m}$ (Akitsu et al., 2015). Most of all validation projects have conducted the in situ observation in small areas at several points, and have expanded the areas by using an airborne/high-resolution-satellite optical observation to the target satellite footprint scale (e.g., Cohen et al., 2006; Sellers et al., 1995; Wang et al., 2004). Such approach is reasonable for the validation of spectral reflectance. Strictly speaking, for the validation of LAI, AGB, and fAPAR, such data in the expanded areas are based on the estimation, not on the in situ observation. Therefore, we have directly conducted the in situ observation at many points in a satellite footprint scale. The spatial scale $(500 \mathrm{~m} \times 500 \mathrm{~m})$ has been specifically chosen for validation of the official products of the Global Change Observation Mission-Climate (GCOM-C) satellite.

We had performed in situ observations of LAI and AGB in this scale at a deciduous needle-leaved forest (DNF), a deciduous broad-leaved forest (DBF), an evergreen needle-leaved forest (ENF), and dry/wet grassland
(DGL, WGL), and discussed the accuracy and the cost (required time and manpower) of several methods used in the observations (Akitsu et al., 2019). Since then, we have expanded our observation network. The observation sites have been established for typical land cover types in East Asia from temperate to cool ecosystems: DNF, ENF, DBF, evergreen broad-leaved forest, DGL, and WGL. The detailed datasets of LAI, AGB, and fAPAR at ENF can be obtained from Akitsu et al. (2020). In this paper, we report the detailed datasets of LAI, AGB, and fAPAR at six sites in deciduous forests and grasslands (GLs): Tomakomai Satellite validation site (TOS, DBF), Fujihokuroku Flux site (FHK, DNF), Watarase flood control basin (WTR, WGL), Baganuur (MBN, DGL), Delgertsogt (DGT, DGL), and Khar Yamaat (KYM, DGL). These datasets, which have been observed at many points (each attaches the data of latitude and longitude) at each site, are definitely unique and useful for validation even for other satellite products, especially with higher spatial resolution, such as the Sentinel-2 satellite.

In DNF, DBF, and GLs, the most accurate and reliable ways of in situ observation of LAI are the direct methods, such as litter-fall trap and leaf clipping. The disadvantages of the reliable clipping methods are generally known that the observations are destructive, thus cannot be repeated at fixed locations (e.g., Jonckheere et al., 2004). Besides, it is too laborious and timeconsuming to conduct the litter-fall and leaf-clipping observations at a large number of points; although a large number of observation points are required to obtain the representative LAI in a satellite footprint scale. In contrast, the accuracy of indirect methods such as using an LAI-2200 (LI-COR Inc.), a digital camera, and a spectroradiometer is controversial (e.g., Jonckheere et al., 2004). Therefore, the LAI obtained using the indirect methods has to be calibrated by using the LAI obtained using a direct method. The advantages of the 
indirect methods are that the observations are not destructive, thus they can be repeated even at fixed locations, and can be conducted easier even at a large number of observation points. To satisfy the accuracy and feasibility of the observation in a large area, we decided to use a combination of direct and indirect methods. First, we obtained the site- or region-specific relationship between the LAI observed by both direct and indirect methods in a limited area. Second, we conducted the observation using an indirect method at a large number of observation points in a large area and obtained the LAI using their relationship. As the combination method, the litter-fall and LAI-2200 methods were conducted in DBF and DNF. In the GLs and understory vegetation in the forests, the clipping method and the spectral observation were conducted. Besides, we investigated the leaf life span (LLS) of Pinus densiflora, which stands in FHK, in order to convert its litter-fall to LAI.

In forests and GLs, AGB was observed using a tree census method and a clipping method, respectively. Our basic sampling was designed to construct many small plots rather than a few large plots. It is because multiple measurements are necessary for accuracy assessment. According to the sampling design, for instance, AGB was observed at 25 plots in the $500 \mathrm{~m} \times 500 \mathrm{~m}$ area at the TOM site. Each plot has a $1,000 \mathrm{~m}^{2}$ area. However, such multiple tree census plots could not be installed at the FHK site due to the legal restraints of the Natural Parks Law. At the FHK site, instead of installing multiple tree census plots, AGB was observed in a large plot with a $200 \mathrm{~m} \times 200 \mathrm{~m}$ area, where tree census had been conducted for the long term. In all tree census plots, we observed the tree height and the diameter at breast height (DBH) of each tree.

In summary, we report the following: (a) LAI and fAPAR at 105 points and AGB at 25 points of a $1,000 \mathrm{~m}^{2}$ area at the TOS site; (b) LAI and fAPAR at 105 points and AGB in a $200 \mathrm{~m} \times 200 \mathrm{~m}$ area at the FHK site; (c) LAI and AGB at 12 to 25 points and fAPAR at 12 points at the WTR site; (d) LAI and AGB at 105 points at the MBN site; (e) LAI and AGB at 51 points at the DGT site; (f) LAI and AGB at 52 points at the KYM site; (g) DBH and tree height for each tree in the tree census area at the TOS and FHK sites; (h) the mean of LAI and AGB in the $500 \mathrm{~m} \times 500 \mathrm{~m}$ area at six observation sites; and (i) the mean of fAPAR in the $500 \mathrm{~m} \times 500 \mathrm{~m}$ area at the TOS, FHK and WTR sites.

\section{2 | DATA DESCRIPTION}

\section{1 | Identifier}

ERDP-2020-16

\section{2 | Contributor}

\subsection{1 | Dataset owner and contact person}

(a) All data except for the following data:

Tomoko Kawaguchi Akitsu:

Faculty of Life and Environmental Sciences, University of Tsukuba, 1-1-1, Tennodai, Tsukuba 305-8572, Japan.tomo.akki878@gmail.com.

(b) Tree census and most of all LAI data at the TOS site:

Tatsuro Nakaji:

Uryu Experimental Forest, Field Science Center for Northern Biosphere, Hokkaido University, Moshiri, Horokanai, Hokkaido 074-0741, Japan.nakaji@fsc.hokudai.ac.jp.

(c) Tree census data at the FHK site:

Tetsuo Okano and Hajime Kobayashi:

Faculty of Agriculture, Shinshu University, Japan. teokano@shinshu-u.ac.jp and kobaafc@shinshu-u.ac.jp, respectively.

\section{3 | Projects}

\subsection{1 | Title}

(a) Validation of land ecology products of GCOM-C (April 2016-March 2019).

(b) Observation for the validation of terrestrial ecological products of GCOM-C (April 2019-March 2022).

\subsection{2 | Personnel}

(a) Principal investigator: Kenlo Nishida Nasahara (116).

(b) Principal investigator: Kenlo Nishida Nasahara (ER2GCF103).

\subsection{3 | Funding}

(a) GCOM: Sixth Research Announcement (April 2016March 2019) of the Japan Aerospace Exploration Agency (JAXA).

(b) Research Announcement on the Earth Observations: EO-RA2 (April 2019-March 2022) of JAXA.

\subsection{Geographical coverage}

Geographic coordinates and descriptions of the six observation sites are listed in Table 1 and Figure 1. 
TABLE 1 Description of the study sites

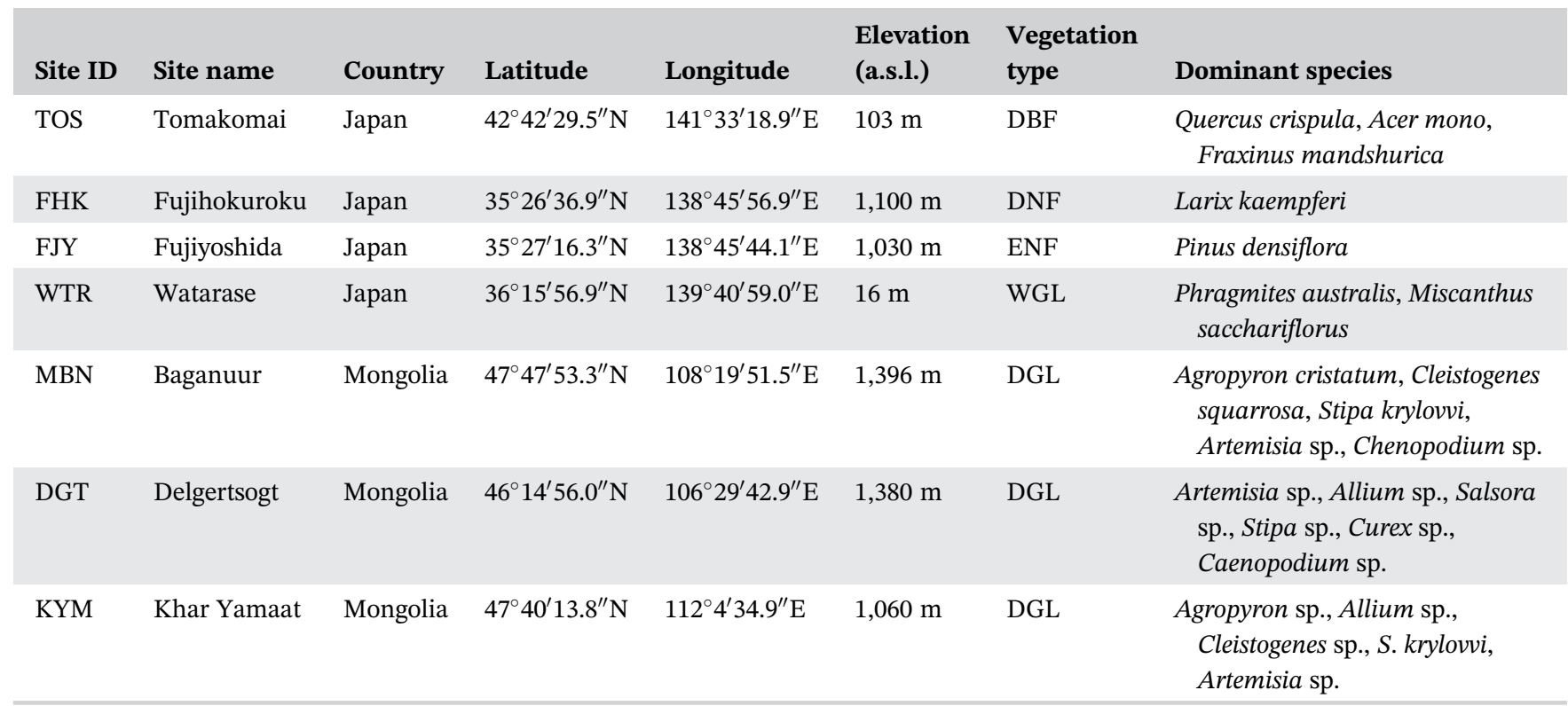

Abbreviations: a.s.l: above sea level; DBF, deciduous broad-leaved forest; DGL, dry grassland; DNF, deciduous needle-leaved forest; ENF, evergreen needle-leaved forest; WGL, wet grassland.

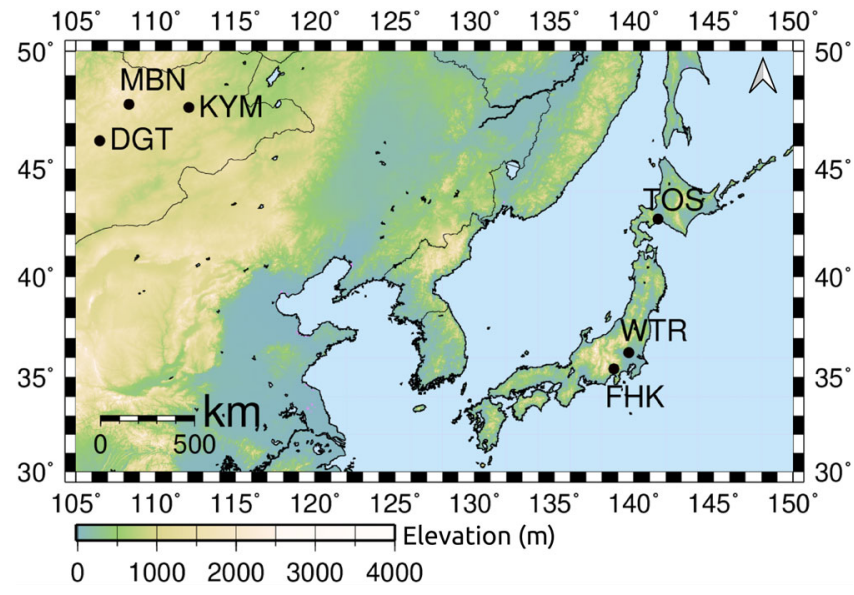

F I G U RE 1 Location of the large-scale ecological observation sites: Tomakomai (TOS), Fujihokuroku (FHK), Watarase (WTR), Baganuur (MBN), Delgertsogt (DGT), and Khar Yamaat (KYM) sites [Color figure can be viewed at wileyonlinelibrary.com]

\subsection{Temporal coverage}

From 2005 to 2019.

\subsection{Methods}

\subsection{1 | Study sites}

Large-scale ecological observation was conducted at six observation sites (the TOS, FHK, WTR, MBN, DGT, and
KYM sites, see Table 1 and Figure 1). We selected the observation sites according to the criteria: flat topography, homogeneous vegetation cover over a $500 \mathrm{~m} \times 500 \mathrm{~m}$ square, and accessibility. Furthermore, we conducted the observation of LLS of $P$. densiflora at the FJY site (Table 1 and Figure 2).

\subsection{2 | Sampling design}

(a) Forest sites:

Five parallel transects were placed at $100 \mathrm{~m}$ intervals, and each transect was $400 \mathrm{~m}$ long (Figure 3a,b). Along each transect, observation points of an LAI and an fAPAR were placed at $20 \mathrm{~m}$ intervals, and tree census points to observe AGB were placed at $100 \mathrm{~m}$ intervals. Furthermore, litter-fall traps were placed to obtain the representative LAI in the observation area (Figures 3a and 4). At the TOS site, tree census area was established in a $1,000 \mathrm{~m}^{2}$ quadrate area centered on the point. At the FHK site, tree census was conducted in a $200 \mathrm{~m} \times 200 \mathrm{~m}$ area (a hatched area in Figure 3b), where it has been conducted for a long term. It is because setting new quadrats for tree census is restricted due to the Natural Parks Law.

(b) WGL site:

Five parallel transects were placed at $100 \mathrm{~m}$ intervals, and each transect was $400 \mathrm{~m}$ long (Figure 3c). Along each transect, observation points of LAI and AGB using a clipping method were placed at $100 \mathrm{~m}$ intervals. fAPAR 


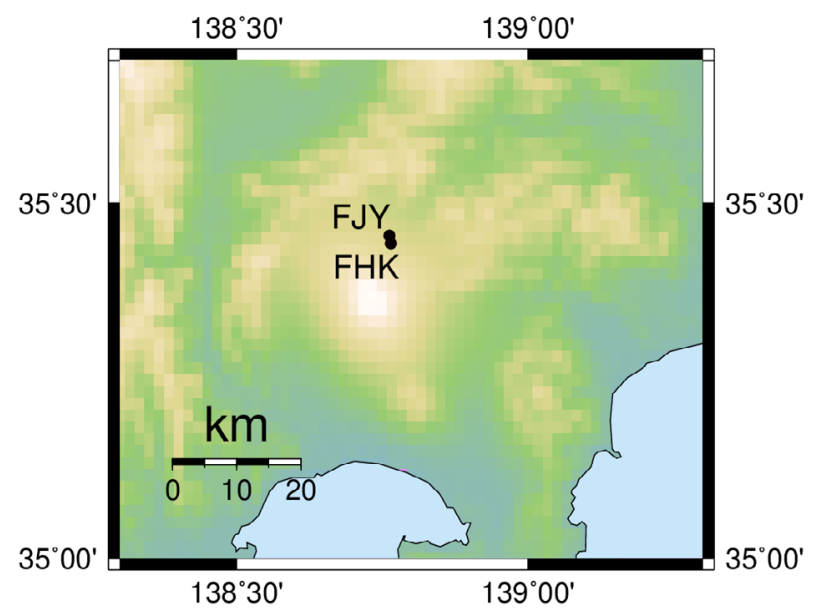

FI G URE 2 Location of the Fujihokuroku (FHK) and Fujiyoshida (FJY) sites [Color figure can be viewed at wileyonlinelibrary.com]

observation points were selected using a random sampling method.

(c) DGL sites:

Five or three parallel transects were placed at $100 \mathrm{~m}$ or $200 \mathrm{~m}$ intervals, respectively, and each transect was $400 \mathrm{~m}$ long (Figure 3d-f). Along each transect, spectral observation points were placed at $20 \mathrm{~m}$ intervals. To obtain the relationship between LAI/AGB and spectral reflectance, 11 observation points for a clipping method were selected.

(d) Observation points' name (observation point ID):

The observation point ID was defined as $A B C D$, where $\mathrm{A}$ is a transect line ID, $\mathrm{B}$ is a direction from the center of the line or that from the tower (E or W meaning east or west, respectively), $\mathrm{CD}(10 \mathrm{~m})$ is a distance from the center of the line or that from the tower (see Figure 3). For instance, the $3 \mathrm{E} 12$ indicates the observation point was located at $120 \mathrm{~m}$ east from the center/ tower on line 3 .

(e) Observation date, its method, and responsible person for each observation:

See Table 2.

\subsection{3 | Observation methods}

(a) Tree census:

At the FHK site, tree census has been conducted every year since 2005 (Table 2). The species name of each tree and its DBH, which was a $1.2 \mathrm{~m}$ height (a Japanese standard DBH), was observed (except for the shrub layer). The tree height of each tree and its position were additionally observed. The tree height was measured every 3 years using an ultrasonic height measuring instrument (Vertex IV, Haglöf Inc.). The position of each tree was surveyed by distance (m) from the southwest corner of the tree census area.

At the TOS site, tree census was conducted in December 2017 (Table 2). The species name of each tree and its DBH, which was a $1.3 \mathrm{~m}$ height (a European standard DBH), were observed except for trees with less than $3 \mathrm{~cm}$ of DBH. Each tree height was estimated using the following allometric equation (Ogawa, 1969) calibrated by using the dataset of DBH and tree height obtained at the TOS site ( $n=76$, where $n$ is the number of trees).

$$
\frac{1}{H}=\frac{1}{a D^{h}}+\frac{1}{H_{\max }},
$$

where $H(\mathrm{~m})$ and $D(\mathrm{~cm})$ are tree height and $\mathrm{DBH}$, respectively. The calibrated parameters $a, h$, and $H_{\max }$ (m) at the TOS site are 2.12, 0.75 and 51.75, respectively. Root mean squared error of the equation was 1.64.

(b) AGB:

AGB for Larix kaempferi $\left(B_{\text {Larix }}\right)$ at the FHK site was calculated by:

$$
\begin{gathered}
B_{\text {Larix }}=B_{\text {Larix_trunk }}+B_{\text {Larix_branches }}+B_{\text {Larix_leaves }}, \\
B_{\text {Larix_trunk }}=0.116680 \times\left(D^{2}\right)^{1.164}, \\
B_{\text {Larix_branches }}=0.000289 \times\left(D^{2}\right)^{1.689}, \\
B_{\text {Larix_leaves }}=0.001113 \times\left(D^{2}\right)^{1.231},
\end{gathered}
$$

where $B_{\text {Larix_trunk }}, B_{\text {Larix_branches, }}$ and $B_{\text {Larix_leaves }}$ are the mass of trunk, branches, and leaves for L. kaempferi, respectively. This equation was specifically made for $L$. kaempferi at the FHK site $(n=10)$.

Except for $L$. kaempferi, the AGB of each tree $i\left(B_{i}\right.$; $\mathrm{kg}$ ) was calculated by the following two steps. First, the $\ln \left(B_{i}\right)$ was calculated using the tree census data as follows:

$$
\ln \left(B_{i}\right)=a+b \times \ln (D)+c \times \ln (H)+d \times \ln (\rho),
$$

where $\rho\left(\mathrm{g} \mathrm{cm}^{-3}\right)$ is a wood specific gravity under ovendry (Table 3), and $a, b, c$, and $d$ are parameters depending on tree species (Table 4). When $H$ was not measured for a deciduous broad-leaved tree, the following formula (Ishihara et al., 2015) was used instead:

$$
\begin{aligned}
\ln \left(B_{i}\right) & =-1.501+1.375 \times \ln (D)+0.464 \\
& \times(\ln (D))^{2}-0.061 \times(\ln (D))^{3}(C F=1.031),
\end{aligned}
$$




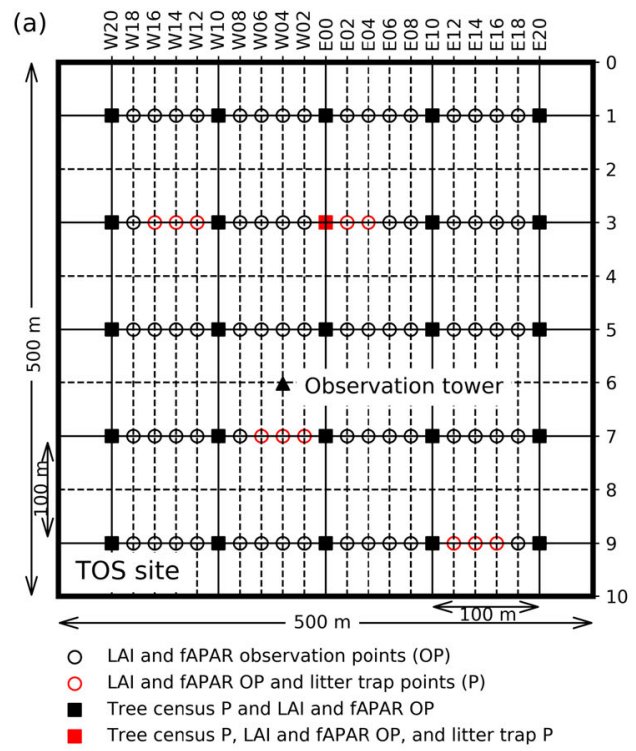

(c)

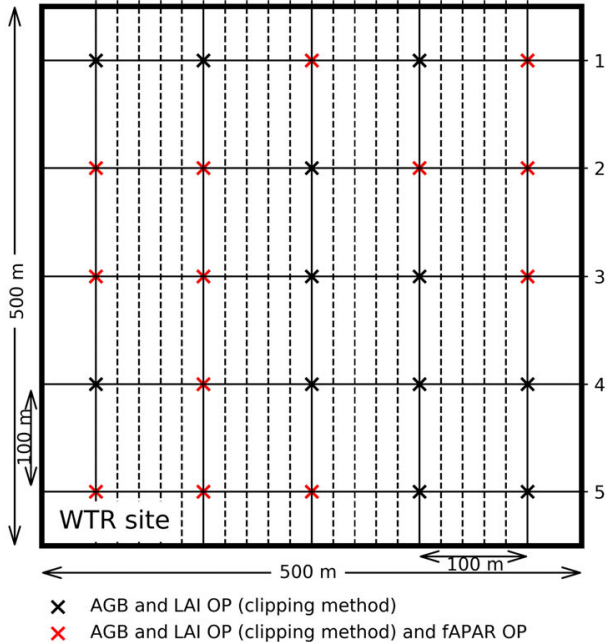

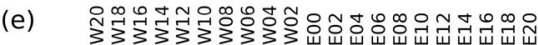

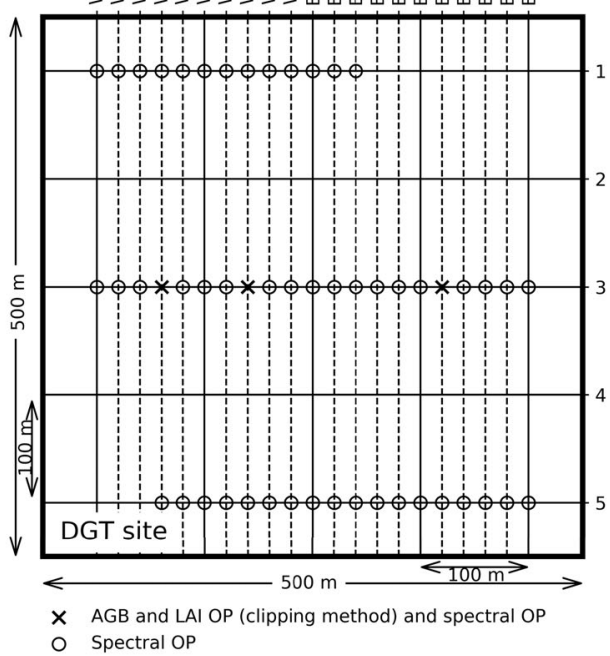

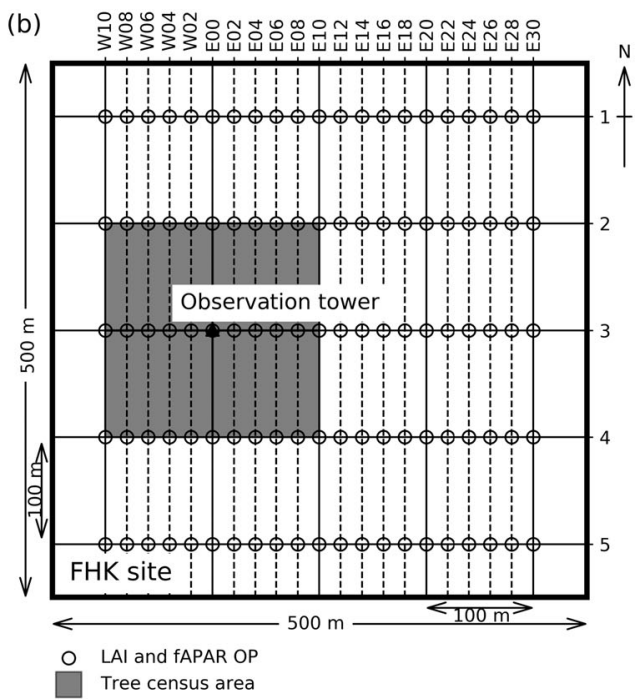

F I G U R E 3 Sampling design of the leaf area index (LAI), the above-ground biomass (AGB) and the fraction of absorbed photosynthetically active radiation (fAPAR) at each site:

(a) Tomakomai (TOS),

(b) Fujihokuroku (FHK),

(c) Watarase (WTR),

(d) Baganuur (MBN), (e)

Delgertsogt (DGT), and (f) Khar Yamaat (KYM) sites [Color figure can be viewed at wileyonlinelibrary.com]

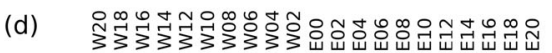

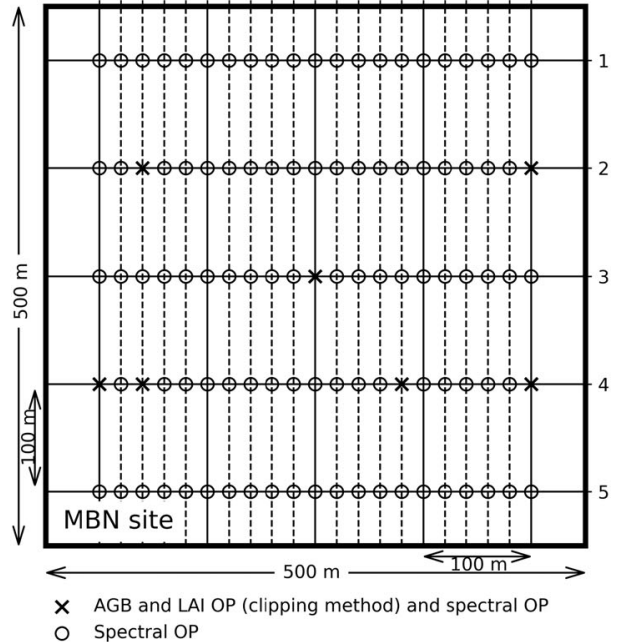

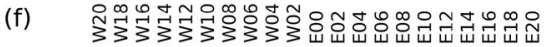

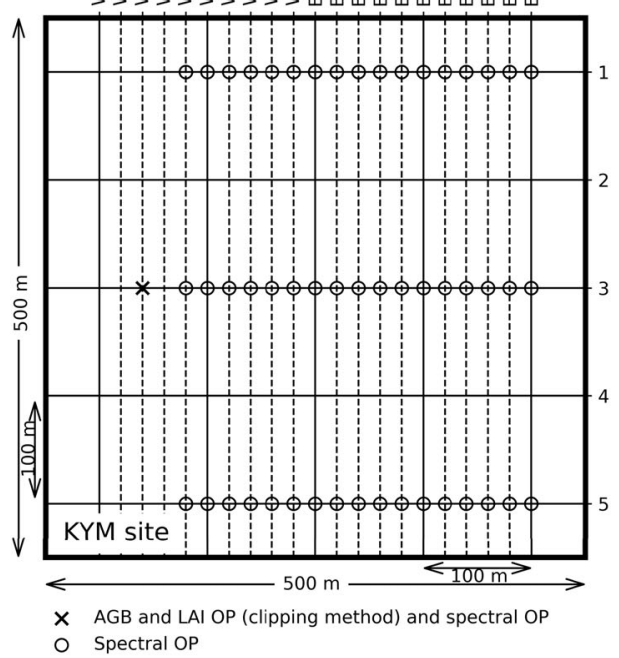

where $C F$ is a correction factor (Sprugel, 1983) described below. Second, to eliminate the bias introduced by inverse logarithmic transformation, $B_{i}$ was obtained as 


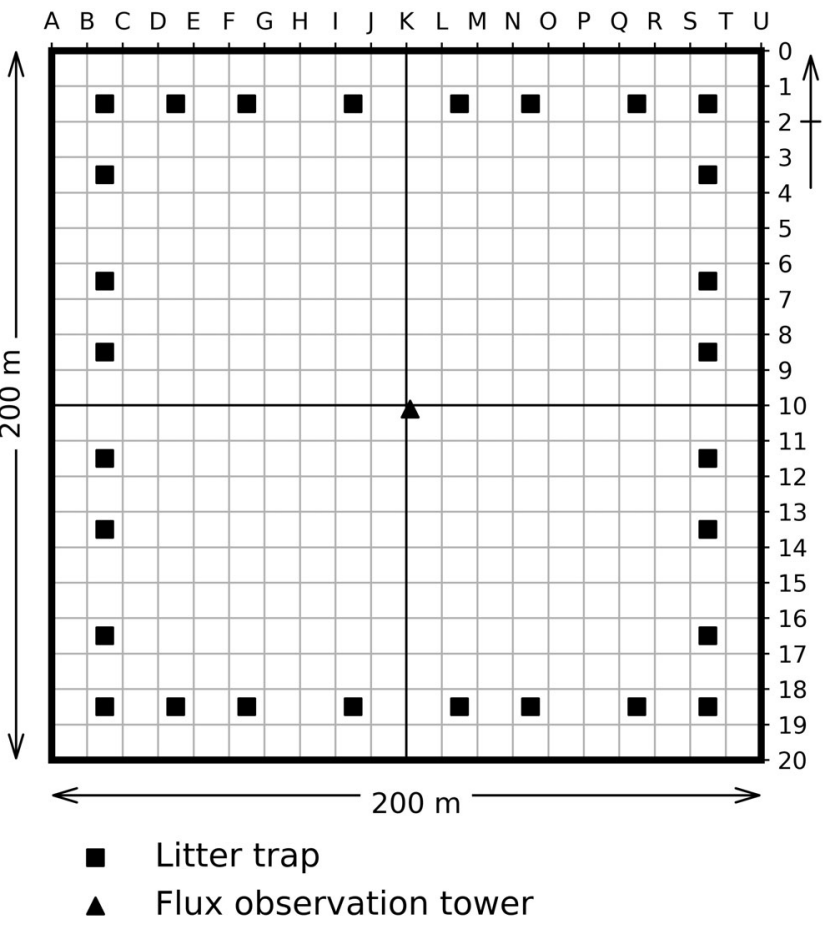

F I G U RE 4 Sampling design within the tree census area at the Fujihokuroku (FHK) site. The alphabets and numbers denote identification names of the observation zone

$$
B_{i}=\exp \left(\widehat{\ln \left(B_{i}\right)}\right) \times C F
$$

where $\widehat{\ln \left(B_{i}\right)}$ is the natural logarithm value of the estimated AGB $B_{i}$ using Equation (6) or (7). $C F$ was calculated by

$$
C F=\exp \left(\frac{S E E^{2}}{2}\right)
$$

where $S E E$ is the standard error of the estimate when the logarithm allometric equation was made. SEE was calculated by

$$
S E E=\sqrt{\frac{\sum_{i=1}^{n}\left(\ln \left(b_{i}\right)-\ln \left(B_{i}\right)\right)^{2}}{n-p}},
$$

where $\ln \left(b_{i}\right)$ is the natural logarithm value of the observed AGB $b_{i}(\mathrm{~kg})$ of a tree, $n$ is the total number of trees which were cut and surveyed to make the allometric equation and $p$ is the number of parameters in the allometric equation.

At the TOS site, AGB was calculated using two allometric equations (Table 4). The allometric equations using an oven-dried $\rho$ ( $\left.\rho_{\text {oven }}\right)$ was basically applied (Tables 3 and 4). When $\rho_{\text {oven }}$ was not available but an airdried $\rho\left(\rho_{\text {air }}\right)$ was available, it was estimated using the following relationship between $\rho_{\text {oven }}$ and $\rho_{\text {air }}$ created using the published data set (Kishima et al., 1962):

$$
\rho_{\text {dried }}=0.9454 \times \rho_{\text {air }}-0.0107\left(n=58, R^{2}=0.9788\right) .
$$

$\operatorname{AGB}\left(B ; \mathrm{Mg} \mathrm{ha}^{-1}\right)$ in each tree census area $\left(A_{\text {tree }} ; \mathrm{m}^{2}\right)$ was calculated by

$$
B=\frac{\sum_{i} B_{i}}{A_{\text {tree }}} \times 10 .
$$

For understory vegetation at the TOS site, AGB ( $B_{\text {clip }}$; $\mathrm{Mg} \mathrm{ha}{ }^{-1}$ ) was observed using a clipping method within nine quadrats. All understory vegetation was cut within each quadrat with a $1 \mathrm{~m} \times 1 \mathrm{~m}$ area. The cut vegetation was completely dried in an oven at $80^{\circ} \mathrm{C}$ for more than $24 \mathrm{hr}$, and their dry weights ( $W_{\text {clip }} ; \mathrm{g}$ ) were measured. $B_{\text {clip }}$ in each clipping area $\left(A_{\text {clip }} ; \mathrm{m}^{2}\right)$ was calculated by

$$
B_{\text {clip }}=\frac{W_{\text {clip }}}{A_{\text {clip }}} \times 10^{-2} \text {. }
$$

At the FHK site, AGB for understory vegetation could not be observed because of the Natural Parks law.

For GL at the WTR site, $B_{\text {clip }}$ was observed at 12 points selected using a random sampling method on June 6,2018 , at 25 points on July 23 and 24, 2018, and at 15 points on Lines 1, 3, and 5 on April 11, 2019. All vegetation was cut in a $50 \mathrm{~cm} \times 50 \mathrm{~cm}$ area at each observation point. The cut vegetation was completely dried in an oven at $70-80^{\circ} \mathrm{C}$ for more than $24 \mathrm{hr}$, and the $W_{\text {clip }}$ was measured. $B_{\text {clip }}$ was calculated using Equation (13).

For GL in Mongolia (the MBN, DGT, and KYM sites), $B_{\text {clip }}$ was observed in 11 quadrats in total (Figure $3 \mathrm{~d}-\mathrm{f}$ ): 10 quadrats had a $50 \mathrm{~cm} \times 50 \mathrm{~cm}$ area, and 1 quadrat had a $25 \mathrm{~cm} \times 25 \mathrm{~cm}$ area. All vegetation was cut in each quadrat. The cut vegetation was completely dried in an oven at $60^{\circ} \mathrm{C}$ for more than $24 \mathrm{hr}$, and the $W_{\text {clip }}$ was measured. $B_{\text {clip }}$ was calculated using Equation (13). Moreover, to obtain AGB at many points, spectral reflectance was observed using the MS-720 spectral radiometer (EKO Instruments B.V.) attaching a $45^{\circ}$ or $25^{\circ}$ collimation tube at 11 quadrats before cutting vegetation (Figure $3 \mathrm{~d}-\mathrm{f}$ ). The spectrum of sky-light $\left(L_{\text {sky }}(\lambda) ; \mathrm{W} \mathrm{m}^{-2} \mu \mathrm{m}^{-1}\right)$ was observed twice before and after observing the spectrum of reflected light from the ground $\left(L_{\mathrm{gr}}(\lambda) ; \mathrm{W} \mathrm{m}^{-2} \mu \mathrm{m}^{-1}\right)$. At the MBN site, $L_{\text {sky }}(\lambda)$ was observed as reflected light from a calibrated whiteboard. It was calculated as follows: 
T A B LE 2 Date, method, and responsible persons for each observation

\begin{tabular}{|c|c|c|c|c|c|}
\hline Site & Observation target & Method & Description & $\begin{array}{l}\text { Observation date (sky } \\
\text { condition) }\end{array}$ & $\begin{array}{l}\text { Responsible } \\
\text { person }\end{array}$ \\
\hline \multirow[t]{7}{*}{ TOS } & \multirow[t]{4}{*}{ LAI of canopy } & \multirow[t]{4}{*}{ LAI-2200 } & \multirow[t]{4}{*}{$2.6 .3(\mathrm{~d})$} & $\begin{array}{l}\text { August } 20 \text { in } 2015 \text { (under } \\
\text { near-perfect cloudy sky) }\end{array}$ & $\begin{array}{l}\text { Akitsu T. K. and } \\
\text { Nakaji T. }\end{array}$ \\
\hline & & & & August 29 in 2016 & Nakaji T. \\
\hline & & & & April 28 in 2017 & Nakaji T. \\
\hline & & & & $\begin{array}{l}\text { August } 2 \text { in } 2019 \text { (before } \\
\text { sunrise) }\end{array}$ & Nakaji T. \\
\hline & LAI of canopy & Litterfall & $2.6 .3(\mathrm{~d})$ & In 2018 & Nakaji T. \\
\hline & LAI and AGB for understory & Clipping method & $2.6 .3(b)$ & August 18, 2015 & Nakaji T. \\
\hline & fAPAR & PAR sensors & $2.6 .3(\mathrm{e})$ & August 7 in 2018 & Akitsu T. K. \\
\hline \multirow[t]{5}{*}{ FHK } & \multirow[t]{3}{*}{ LAI of canopy } & LAI-2000 & $2.6 .3(\mathrm{~d})$ & $\begin{array}{l}\text { August 28, } 2014 \text { (under near- } \\
\text { perfect cloudy sky) }\end{array}$ & $\begin{array}{l}\text { Akitsu T. K. and } \\
\text { Honda Y. }\end{array}$ \\
\hline & & LAI-2000 & $2.6 .3(\mathrm{~d})$ & $\begin{array}{l}\text { Sep } 21 \text { in } 2015 \text { (under near- } \\
\text { perfect cloudy sky) }\end{array}$ & $\begin{array}{l}\text { Honda Y. and } \\
\text { Akitsu T. K. }\end{array}$ \\
\hline & & LAI-2200 & $2.6 .3(\mathrm{~d})$ & $\begin{array}{l}\text { August 2, } 2018 \text { (under near- } \\
\text { perfect cloudy sky) }\end{array}$ & Akitsu T. K. \\
\hline & LAI of canopy & Litterfall & $2.6 .3(\mathrm{~d})$ & In 2018 & Kobayashi H. \\
\hline & LAI of understory & LAI-2200 & $2.6 .3(\mathrm{~d})$ & $\begin{array}{l}\text { August 2, } 2018 \text { (under near- } \\
\text { perfect cloudy sky) }\end{array}$ & Akitsu T. K. \\
\hline FJY & LLS & $\begin{array}{l}\text { Counting leaf } \\
\text { number }\end{array}$ & $2.6 .3(\mathrm{c})$ & August 2, 2018 & $\begin{array}{l}\text { Akitsu T. K., } \\
\text { Kobayashi H., } \\
\text { Nakano T, and } \\
\text { Nakano T. }\end{array}$ \\
\hline \multirow[t]{4}{*}{ WTR } & \multirow[t]{2}{*}{ LAI and AGB } & \multirow[t]{2}{*}{ Clipping method } & \multirow[t]{2}{*}{ 2.6.3 (b) and (d) } & June 6 and July 23-24, 2018 & $\begin{array}{l}\text { Akitsu T. K. and } \\
\text { Terigele }\end{array}$ \\
\hline & & & & April 11, 2019 & Akitsu T. K. \\
\hline & fAPAR & PAR sensors & $2.6 .3(\mathrm{e})$ & June 6, 2018 & Akitsu T. K. \\
\hline & $\begin{array}{l}\text { Reflectance of PAR from the } \\
\text { canopy }\end{array}$ & $\begin{array}{l}\text { PAR sensors } \\
\text { mounted on a } \\
\text { drone }\end{array}$ & $2.6 .3(\mathrm{e})$ & May 21, 2018 & $\begin{array}{l}\text { Honda Y. and } \\
\text { Kajiwara K. }\end{array}$ \\
\hline MBN & LAI and AGB & $\begin{array}{l}\text { Clipping method } \\
\text { and MS-720 }\end{array}$ & 2.6.3 (b) and (d) & August 22-24, 2018 & Akitsu T. K. \\
\hline DGT & LAI and AGB & $\begin{array}{l}\text { Clipping method } \\
\text { and MS-720 }\end{array}$ & 2.6.3 (b) and (d) & August 8-9, 2018 & $\begin{array}{l}\text { Akitsu T. K. and } \\
\text { Bayarsaikhan } \\
\text { U. }\end{array}$ \\
\hline KYM & LAI and AGB & $\begin{array}{l}\text { Clipping method } \\
\text { and MS-720 }\end{array}$ & 2.6.3 (b) and (d) & August 13, 2018 & $\begin{array}{l}\text { Akitsu T. K. and } \\
\text { Bayarsaikhan U. }\end{array}$ \\
\hline
\end{tabular}

Note: The initials of the responsible persons' names are corresponding to the authors' names.

Abbreviations: AGB, above-ground biomass; fAPAR, fraction of absorbed photosynthetically active radiation; LAI, leaf area index; LLS, leaf life span. 
T A B L E 3 Above-ground biomass (AGB) estimation method and wood specific gravity ( $\rho$ ) for each tree species

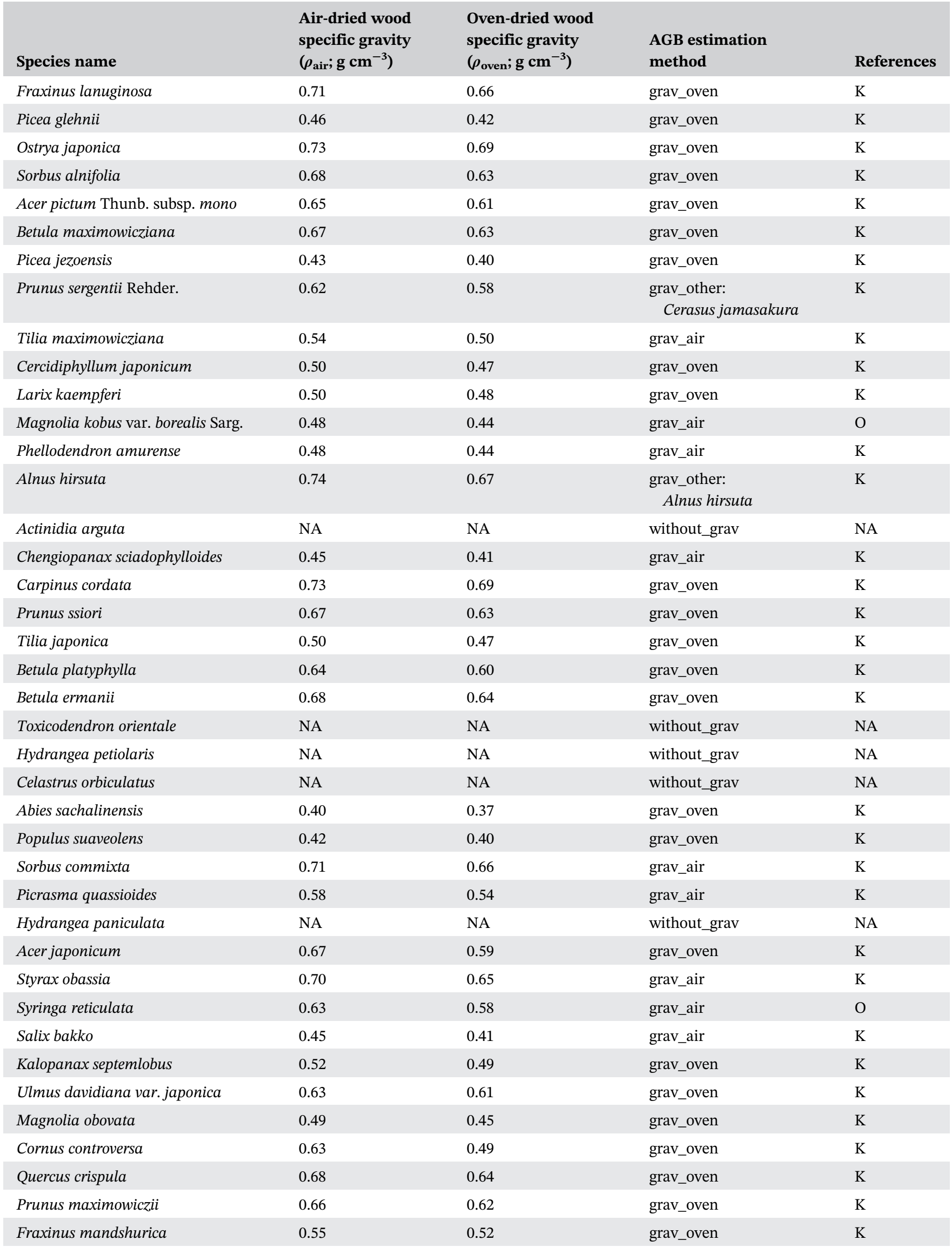


T A B L E 3 (Continued)

\begin{tabular}{lllll} 
& $\begin{array}{l}\text { Air-dried wood } \\
\text { specific gravity } \\
\left(\rho_{\text {air }} ; \mathbf{g ~ c m}^{-3}\right)\end{array}$ & $\begin{array}{l}\text { Oven-dried wood } \\
\text { specific gravity } \\
\left(\rho_{\text {oven }} ; \mathbf{g ~ c m}^{-3}\right)\end{array}$ & $\begin{array}{l}\text { AGB estimation } \\
\text { method }\end{array}$ \\
\hline Species name & 0.62 & 0.58 & grav_oven \\
\hline Morus australis & NA & NA & without_grav \\
\hline Vitis coignetiae & 0.64 & 0.59 & grav_air \\
\hline Acre palmatum var. mastumurae & NA & O \\
\hline
\end{tabular}

Note: "grav_oven" indicates that AGB was calculated using a $\rho_{\text {oven }}$, "grav_air" indicates that AGB was calculated using a $\rho_{\text {oven }}$ estimated from a $\rho_{\text {air }}$ and "without_grav" indicates that AGB was calculated without using $\rho$. "K" means Kishima, Okamoto, and Hayashi (1962) and "O" means a $\rho_{\text {air }}$ was observed at the TOS site. "NA" means not available.

T A B L E 4 Parameters, determination coefficient $\left(R^{2}\right)$ and correction factor $(C F)$ of allometric equations of above-ground biomass (AGB)

\begin{tabular}{|c|c|c|c|c|c|c|c|c|}
\hline Site & Species name or plant type & $a$ & $\boldsymbol{b}$ & c & $d$ & $R^{2}$ & CF & $\begin{array}{l}\text { Literature for the } \\
\text { AGB estimation model }\end{array}$ \\
\hline \multirow[t]{2}{*}{ FHK } & $\begin{array}{l}\text { Evergreen needle-leaved tree } \\
\text { except for Larix kaempferi }\end{array}$ & -2.356 & 2.157 & 0.247 & 0 & NA & 1.033 & Ishihara et al. (2015) \\
\hline & Deciduous broad-leaved tree & -2.407 & 2.141 & 0.390 & 0 & NA & 1.033 & Ishihara et al. (2015) \\
\hline TOS & Most of all trees & -1.876 & 2.174 & 0.283 & 0.611 & NA & 1.031 & Ishihara et al. (2015) \\
\hline
\end{tabular}

Abbreviation: NA, not available.

$$
L_{\mathrm{sky}}(\lambda)=\frac{L_{\mathrm{sky} 1}(\lambda)+L_{\mathrm{sky} 2}(\lambda)}{2},
$$

where $L_{\text {sky } 1}(\lambda)$ and $L_{\text {sky } 2}(\lambda)$ are $L_{\text {sky }}(\lambda)$ observed before and after observing $L_{\mathrm{gr}}(\lambda)$, respectively. At the DGT and KYM site, $L_{\text {sky }}(\lambda)$ was observed as reflected light from four sheets of filter paper with a $300 \mathrm{~mm}$ diameter. It was calculated by

$$
L_{\text {sky }}(\lambda)=\frac{L_{\text {sky } 1}(\lambda)+L_{\text {sky } 2}(\lambda)}{2 \times R_{4 \text { paper }}(\lambda)},
$$

where $R_{4 \text { paper }}(\lambda)\left(\mathrm{W} \mathrm{m}^{-2} \mu \mathrm{m}^{-1}\right)$ is a spectral reflectance of four sheets of filter paper. $R_{4 \text { paper }}(\lambda)$ was observed using the spectroradiometer FieldSpec 3 (ASD Inc.) and the integrating sphere LI-1800-12 (LI-COR Inc.).

To obtain the relationship between AGB and spectral reflectance, normalized difference vegetation index (NDVI) was calculated by

$$
N D V I=\frac{R_{\mathrm{NIR}}-R_{\text {red }}}{R_{\mathrm{NIR}}+R_{\text {red }}},
$$

where $R_{\text {red }}$ and $R_{\mathrm{NIR}}\left(\mathrm{W} \mathrm{m}^{-2} \mu \mathrm{m}^{-1}\right)$ are a reflectance of red light and that of near-infrared (NIR) light, respectively. $R_{\text {red }}$ and $R_{\mathrm{NIR}}$ were calculated as a band reflectance of the Second generation GLobal Imager (SGLI) mounted on the GCOM-C satellite as follows:

$$
\begin{aligned}
R_{\mathrm{red}}= & \frac{\int_{\lambda} L_{\mathrm{gr}}(\lambda) \times R S R_{7}(\lambda) \mathrm{d} \lambda}{\int_{\lambda} L_{\mathrm{sky}}(\lambda) \times R S R_{7}(\lambda) \mathrm{d} \lambda}, \\
R_{\mathrm{NIR}}= & \frac{\int_{\lambda} L_{\mathrm{gr}}(\lambda) \times R S R_{10}(\lambda) \mathrm{d} \lambda}{\int_{\lambda} L_{\mathrm{sky}}(\lambda) \times R S R_{10}(\lambda) \mathrm{d} \lambda},
\end{aligned}
$$

where $R S R_{7}$ and $R S R_{10}$ are the relative spectral response of Bands 7 and 10 of the SGLI, respectively. AGB estimated using NDVI $\left(B_{\mathrm{NDVI}}\right)$ was calculated using the relationship between AGB and NDVI (Figure 5a) at many points by

$$
B_{\mathrm{NDVI}}=0.1240 \times \exp (3.4062 \times N D V I) .
$$

\section{(c) LLS of P. densiflora:}

LLS of $P$. densiflora, which was needed to calculate LAI from litters collected at the FHK site, was observed at the Fujiyoshida forest meteorology research site (FJY) belonging to AsiaFlux and JaLTER networks (http://asiaflux.net/ and http://jalter.org/, respectively) on August 2, 2018. The leaves of $P$. densiflora were accessible from the ecological observation tower at the FJY site, which is approximately $1.25 \mathrm{~km}$ away from the FHK site (see Figure 2). 
(a)

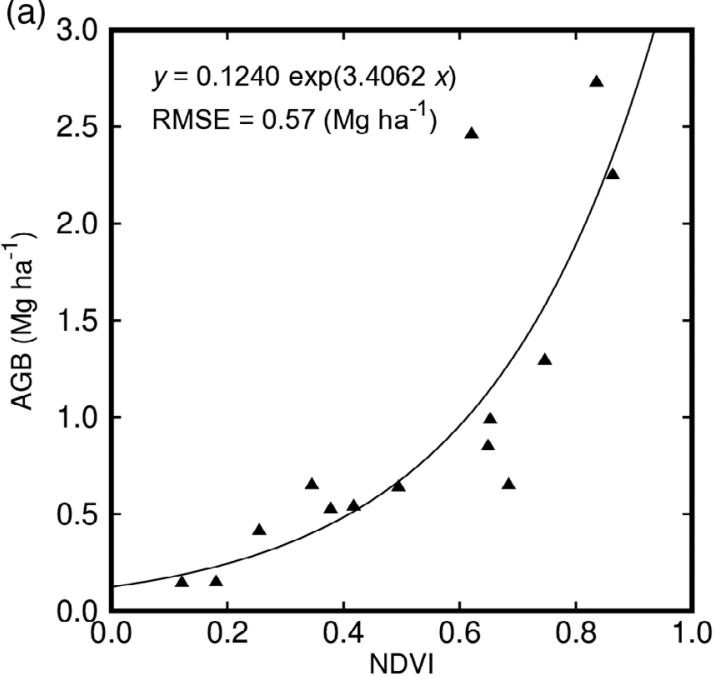

(b)

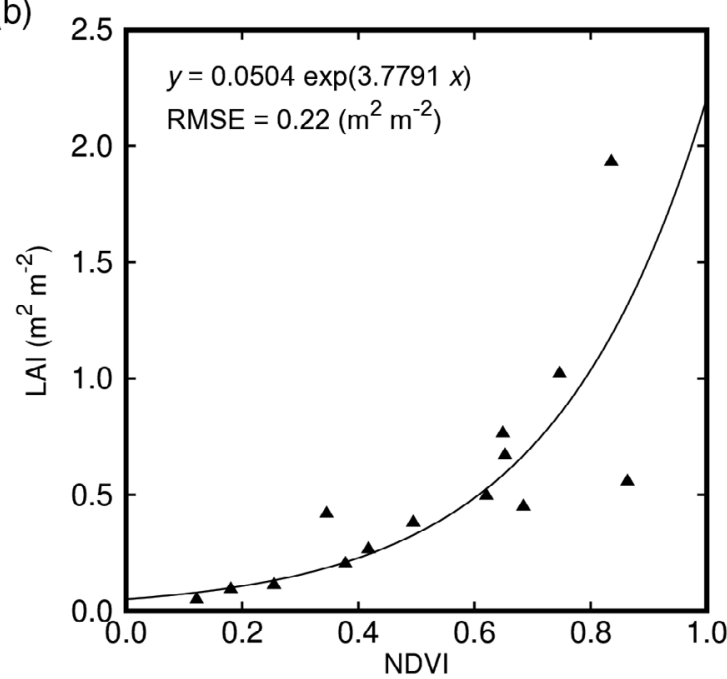

F I G U RE 5 Relationships (a) between the normalized difference vegetation index (NDVI) and the above-ground biomass (AGB) and (b) between NDVI and the leaf area index (LAI) in Mongolia. RMSE denotes the root mean squared error

Ten branches were cut from a sunny (upper) part. The other 10 branches were cut from a shaded (lower) part. The number of leaves on each branch was counted depending on leaf age. The age of current leaves was counted as 0 year. As a result, most of all sun leaves have been alive for two growing seasons (Figure 6). For the shade leaves, the number of leaves that were born and grown varies depending on the year; however, they have been alive at least for two growing seasons. Although additional studies might be needed to obtain the accurate LLS, we roughly estimated the leaves of $P$. densiflora might be alive for two growing seasons or more.

(d) LAI:

LAI was defined as the projected (one-sided) green leaf area divided by the ground surface area beneath those leaves. In DGL, LAI was defined as the projected green leaf and stem area divided by the ground surface area since the leaves and stems were too tiny to be divided into each part.

At the TOS and FHK sites, LAI of canopy $\left(L A I_{\mathrm{C}_{\perp} 2200}\right.$; $\left.\mathrm{m}^{2} \mathrm{~m}^{-2}\right)$ and that of understory $\left(L A I_{\mathrm{u} \_2200} ; \mathrm{m}^{2} \mathrm{~m}^{-2}\right)$ were observed using LAI-2200C (LI-COR Inc.) or LAI-2000 (LICOR Inc.) under the near-perfect cloudy sky or before sunrise (Table 2). $L A I_{\mathrm{c}_{-} 2200}$ and $L A I_{\mathrm{u}_{-} 2200}$ were observed at 105 observation points. Since the LAI-2200C's data are a set of five light data obtained from five rings, if a set of the data contained one or more zero data, the set was excluded from the analysis.

At the TOS site, $L A I_{\mathrm{c} \_2200}$ was calculated as follows:

$$
\mathrm{LAI}_{\mathcal{C}_{-} 2200}=\mathrm{PAI}_{\mathcal{C}_{-} 2200}-\mathrm{PAI}_{\text {leafless }},
$$

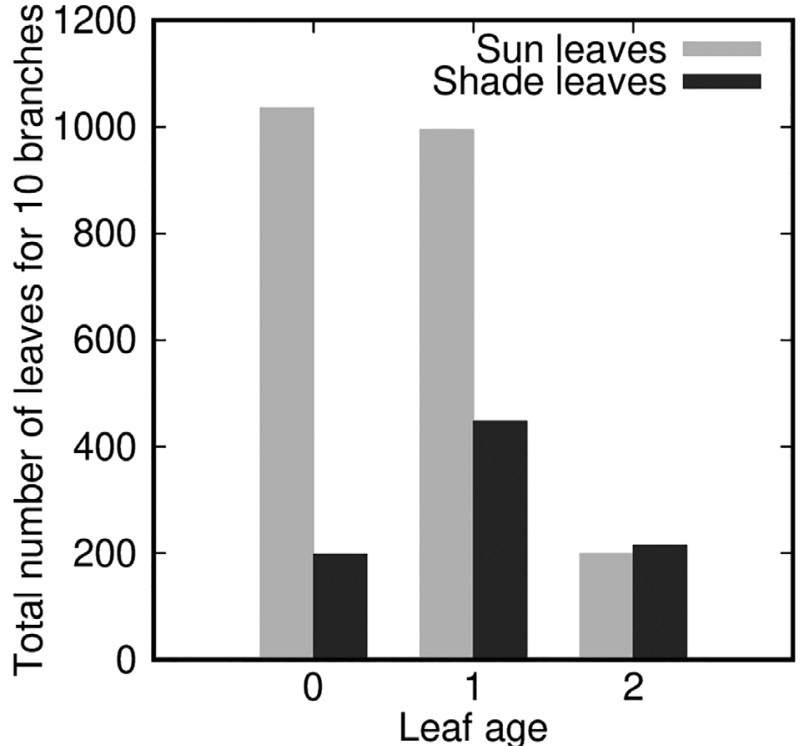

F I G U RE 6 Total number of leaves for each age on 10 branches of Pinus densiflora

where $P A I_{\text {leafless }}$ and $P A I_{c_{\_} 2200}$ are plant area indices observed using the LAI-2200C during the leafless and leafy seasons, respectively. To obtain the accurate LAI, a correction factor $\left(C F_{\mathrm{c}}\right)$ of $L A I_{\mathrm{c}_{-} 2200}$ was obtained at litterfall traps in 2016 (Figure 3a): LAI was observed from the litter-fall $\left(L A I_{\text {litter }}\right)$. It was also observed using the LAI$2200 \mathrm{C}$ in the leafless and the leafiest seasons over each litter-fall trap ( $\left.L A I_{2200 \_l i t t e r}\right)$. $L A I_{2200 \_l i t t e r}$ was calculated by 


$$
\mathrm{LAI}_{2200 \_ \text {litter }}=\mathrm{PAI}_{C_{-} 2200}-\mathrm{PAI}_{\text {leafless }} \text {. }
$$

The litters were collected several times during the growing season. The collected litters were dried in an oven at $80^{\circ} \mathrm{C}$, and the weight ( $W_{\text {litter }} ; \mathrm{g}$ ) was measured. $L A I_{\text {litter }}$ was estimated from the leaf mass area (LMA; $\mathrm{g} \mathrm{m}^{-2}$ ) and basal area density of target trees around the litter-fall trap (Ishihara \& Hiura, 2011). $L A I_{\text {litter }}$ was calculated by

$$
L A I_{\text {litter }}=\frac{W_{\text {litter }}}{L M A \times G A_{\text {traps }}},
$$

where $G A_{\text {traps }}\left(\mathrm{m}^{2}\right)$ is a total ground area of litter-fall traps. Using the $L A I_{\text {litter }}$ and $L A I_{2200 \_l i t t e r}, C F_{\mathrm{c}}$ was calculated by

$$
C F_{\mathrm{c}}=\frac{L A I_{\text {litter }}}{L A I_{2200 \_ \text {litter }}} .
$$

As a result, $C F_{\mathrm{c}}$ was 0.96 at the TOS site. Eventually, LAI of canopy $\left(L A I_{\mathrm{c}}\right)$ was obtained as

$$
L A I_{\mathrm{c}}=L A I_{c_{-} 2200} \times C F_{\mathrm{c}} .
$$

At the FHK site, Equation (20) could not be adopted because of the existence of evergreen needle-leaved trees. A correction factor $\left(C F_{\mathrm{c}}\right)$ of $L A I_{\mathrm{c} \_2200}$ was obtained at litter-fall traps, where $L A I_{\text {litter }}$ and $L A I_{2200 \_l i t t e}$ were observed (Figure 4). $L A I_{\text {litter }}$ was calculated as follows:

$$
L A I_{\text {litter }}=\frac{\left(\frac{W_{\text {litter larch }}}{L M A_{\text {larch }}}+\frac{W_{\text {litter pini }} \times 2}{L M A_{\text {pine }}}+\frac{W_{\text {litter other }}}{L M A_{\text {other }}}\right)}{G A_{\text {traps }}},
$$

where $W_{\text {litter_larch }}, W_{\text {litter_pine, }}$ and $W_{\text {litter_other }}(\mathrm{g})$ are the dry weights of litters of $L$. kaempferi, $P$. densiflora, and the other trees, respectively. They were measured after drying them at $80^{\circ} \mathrm{C}$ for $48 \mathrm{hr}$ in an oven. $L M A_{\text {larch }}$, $L M A_{\text {pine }}$, and $L M A_{\text {other }}\left(\mathrm{g} \mathrm{m}^{-2}\right)$ are LMA of L. kaempferi $\left(66.81 \mathrm{~g} \mathrm{~m}^{-2}\right)$, P. densiflora $\left(64.47 \mathrm{~g} \mathrm{~m}^{-2}\right)$, and the other trees (65.63 $\mathrm{g} \mathrm{m}^{-2}$, which is LMA of Quercus crispula as a representative value of the other trees), respectively. To obtain their LMA, dry weight for each species was measured, and the leaves' area was measured after infiltrating the leaves with water. $C F_{\mathrm{c}}$ was calculated using Equation (23). As a result, $C F_{\mathrm{c}}$ was 1.33 at the FHK site. In Equation (25), the leaves area of $P$. densiflora was doubled because of its LLS (see the previous subsection). $L A I_{\mathrm{c}}$ was calculated using Equation (24).

At the TOS site, LAI of understory $\left(L A I_{\mathrm{u}}\right)$ was obtained using $L A I_{\mathrm{u}_{\_} 2200}$ and the correction factor of $L A I_{\mathrm{u}-2200}$ obtained at northern Hokkaido $\left(C F_{\mathrm{u}}=0.79\right.$; Akitsu et al., 2020) as follows:

$$
L A I_{\mathrm{u}}=L A I_{u_{\_} 2200} \times C F_{\mathrm{u}} .
$$

On the other hand, at the FHK site, $L A I_{\mathrm{u}-2200}$ was directly adopted as $L A I_{\mathrm{u}}$.

In DGLs in Mongolia (i.e., the MBN, GDT, and KYM sites), LAI ( $\left.L A I_{\text {clip }}\right)$ was observed in 11 quadrats in total (see the details at the subsection 2.6.3 (b)). All vegetation was cut within each quadrat, and the cut vegetation was divided into leaves and the others on sites. Fresh leaves area was observed using digital images captured by a digital camera or an image scanner. The images were taken including a coin. The pixel number of the leaf part $\left(P N^{\text {leaf }}\right)$ was counted from the images using a threshold method. Leaves area in each quadrat $\left(L A ; \mathrm{cm}^{2}\right)$ was calculated as follows:

$$
L A=\sum_{i=1}^{n} \frac{P N_{i}^{\text {leaf }} \times C A}{P N_{i}^{\text {coin }}}
$$

where $n$ is a total number of images at each quadrat, $C A$ $\left(\mathrm{cm}^{2}\right)$ is an already-known coin area and $P N^{\text {coin }}$ is a pixel number of a coin part. LAI at each quadrat was calculated by

$$
L A I=\frac{L A}{G A},
$$

where $G A\left(\mathrm{~cm}^{2}\right)$ is the ground area of a quadrat. Furthermore, to obtain LAI at many points, $R(\lambda)$ was additionally observed using the MS-720 (Figure 3d-f). Using the relationship between LAI and NDVI, which was calculated by Equation (16) (Figure 5b), LAI was estimated from the MS-720's data $\left(L A I_{\text {MS720 }}\right)$ by

$$
L A I_{\mathrm{MS} 720}=0.0504 \times \exp (3.7791 \times N D V I) .
$$

In a WGL (i.e., the WTR site), LAI was observed using a clipping method. The number of observation points was described in the subsection 2.6.3 (b). All vegetation was cut in a $50 \mathrm{~cm} \times 50 \mathrm{~cm}$ area at each observation point. The cut vegetation was divided into leaves and the others. Fresh leaves area $\left(L A_{\mathrm{LAI}-3100} ; \mathrm{cm}^{2}\right)$ was measured using an area meter LAI-3100C (LI-COR Inc.). On June 6, 2018, and April 11, 2019, all of the clipped leaves were measured. Leaves area within each quadrat $\left(L A ; \mathrm{cm}^{2}\right)$ was calculated as follows:

$$
L A=\frac{L A I_{\mathrm{LAI}-3100} \times 10}{D A_{\mathrm{LAI}-3100}},
$$

where $D A_{\mathrm{LAI}-3100}\left(\mathrm{~cm}^{2}\right)$ is a $10-\mathrm{cm}^{2}$ disk area measured using the LAI-3100C. In contrast, on July 23 and 
(a)

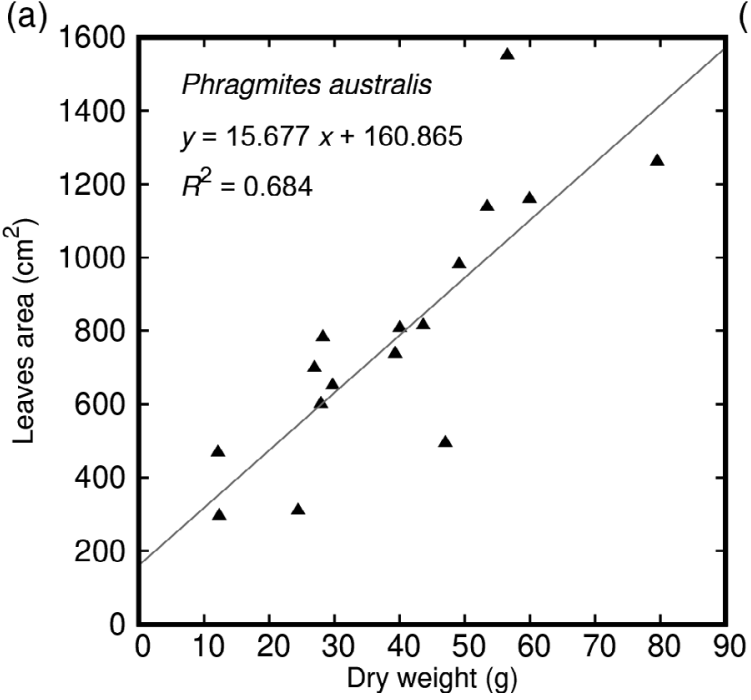

(b)

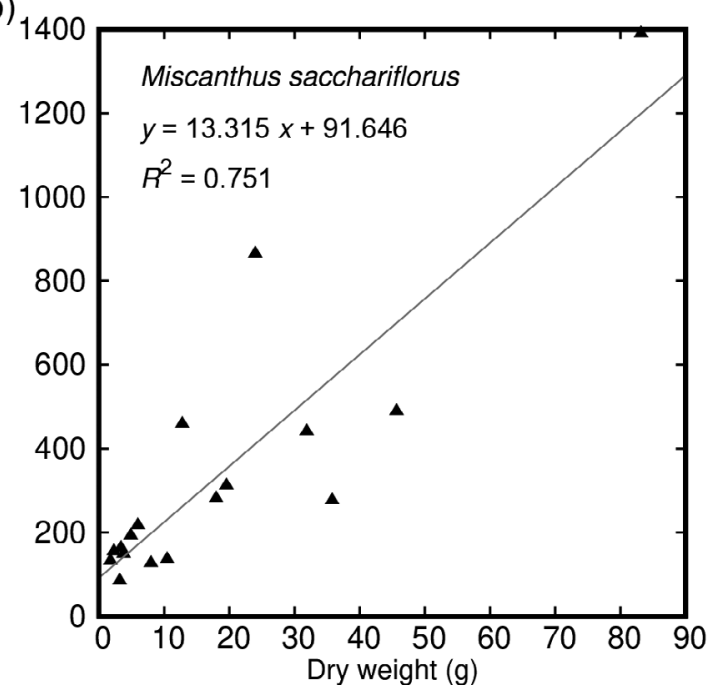

FI G U R E 7 Relationships between leaves area and dry weight of (a) Phragmites australis and (b) Miscanthus sacchariflorus

24, 2018, a part of the clipped leaves was not directly measured using the LAI-3100C. It is because there was more vegetation than we can handle the direct measurement for all. Therefore the relationships between leaves area and dry weight of dominant species (i.e., Phragmites australis and Miscanthus sacchariflorus) were obtained in the WTR site (Figure 7), and leaves areas of $P$. australis and $M$. sacchariflorus ( $L A_{\text {Phra. }}$ and $L A_{\text {Misc.; }} \mathrm{cm}^{2}$, respectively) were estimated using the relationships. They were calculated as follows:

$$
\begin{aligned}
& L A_{\text {Phra. }}=15.677 \times D W_{\text {Phra. }}+160.865(n=16), \\
& L A_{\text {Misc. }}=13.315 \times D W_{\text {Misc. }}+91.646(n=17),
\end{aligned}
$$

where $D W_{\text {Phra. }}$ and $D W_{\text {Misc. }}(\mathrm{g})$ are the dry weights of $P$. australis and $M$. sacchariflorus in each quadrat, respectively. For the other species, all of the leaves area ( $L A_{\text {others }}$; $\mathrm{cm}^{2}$ ) was directly measured. $L A$ was calculated by

$$
L A=L A_{\text {Phra. }}+L A_{\text {Misc. }}+L A_{\text {others }} .
$$

LAI in each quadrat was calculated by Equation (28). (e) fAPAR:

Photosynthetically active radiation (PAR) was observed using the LI-190 (LI-COR Inc.), LI-190R (LICOR Inc.), and the PAR-02D (Prede Co., Ltd.) at the TOS, FHK, and WTR sites (Figure 3a-c).

At the TOS and FHK sites, above the canopy, we observed incoming PAR ( PAR $\left._{\text {above }} \downarrow\right)$ using an LI-190 encased in a weather-proof external housing with a glass dome (Hukseflux), which we call Encased LI-190. The Encased LI-190 was installed on the top of the tower. Reflecting PAR from the canopy ( $\mathrm{PAR}_{\text {above }} \uparrow$ ) was observed using the PAR-02D and the Encased LI-190 installed on the top of the tower at the TOS and FHK sites, respectively. Under the canopy, we observed downward and upward PAR ( $\mathrm{PAR}_{\text {middle }} \downarrow$ and $\mathrm{PAR}_{\text {middle }} \uparrow$, respectively) using the LI-190R equipped with the LAI-2200C. Further-

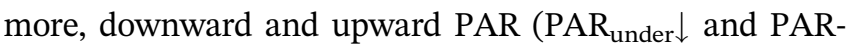
under $\uparrow$, respectively) were observed under the understory vegetation. The PAR observation was conducted at each observation point as the following sequences: (a) $\mathrm{PAR}_{\text {middle }} \downarrow$ and $\mathrm{PAR}_{\text {middle }} \uparrow$ in synchronization with the observation of PAR above $\downarrow$ and $\mathrm{PAR}_{\text {above }} \uparrow$, (b) PAR middle $\downarrow$ and $\mathrm{PAR}_{\text {middle }} \uparrow$ over the target understory, (c) $\mathrm{PAR}_{\text {under }} \downarrow$ and $\mathrm{PAR}_{\text {under }} \uparrow$ under the target understory, and (d) PARmiddle $\downarrow$ and $\mathrm{PAR}_{\text {middle }} \uparrow$ over the target understory.

All of the used PAR sensors were calibrated with the accurate PAR which was observed using two spectroradiometers (MS-700, EKO instruments B.V.) applying the direct and diffuse separate observation method (Akitsu, Nasahara, Hirose, Ijima, \& Kume, 2017).

An fAPAR was calculated at each observation point. fAPAR of the canopy ( $f A P A R_{\text {canopy }}$; unitless) was calculated by

$f A P A R_{\text {canopy }}=\frac{P A R_{\text {above }} \downarrow-P A R_{\text {above }} \uparrow-P A R_{\text {middle }} \downarrow+P A R_{\text {middle }} \uparrow}{P A R_{\text {above }} \downarrow}$.

Here, fAPAR of the understory ( $f A P A R_{\text {under }}$; unitless) at each observation point was calculated by

$$
\begin{aligned}
& f A P A R_{\text {under }} \\
& =\frac{P A R_{\text {middle }} \downarrow-P A R_{\text {middle }} \uparrow-P A R_{\text {under }} \downarrow+P A R_{\text {under }} \uparrow}{P A R_{\text {middle }} \downarrow} .
\end{aligned}
$$


T A B L E 5 Names of data files and their descriptions

\begin{tabular}{|c|c|}
\hline Data file names & Descriptions \\
\hline 2017_tree_census_TOS_Nakaji.csv & Tree census data in 2017 at TOS site. \\
\hline 2017_AGB_TOS_Akitsu.csv & $\begin{array}{l}\text { AGB observed in } 2017 \text { at each observation point at } \\
\text { TOS site. }\end{array}$ \\
\hline 2015_LAI-2200_canopy_TOS_Akitsu.csv & $\begin{array}{l}\text { LAI of canopy obtained using the LAI- } 2200 \text { on August } \\
20,2015 \text { at TOS site. }\end{array}$ \\
\hline 2016_LAI-2200_canopy_TOS_Nakaji.csv & $\begin{array}{l}\text { LAI of canopy obtained using the LAI- } 2200 \text { on August } \\
29,2016 \text { at TOS site. }\end{array}$ \\
\hline 2018_LAI-2200_canopy_TOS_Nakaji.csv & $\begin{array}{l}\text { LAI of canopy obtained using the LAI- } 2200 \text { on April } \\
\text { 11, May 25, June 19, August 7, and October 18, } 2018 \\
\text { at TOS site. }\end{array}$ \\
\hline 2019_LAI-2200_canopy_TOS_Nakaji.csv & $\begin{array}{l}\text { LAI of canopy obtained using the LAI-2200 on August } \\
\text { 2, } 2019 \text { at TOS site. }\end{array}$ \\
\hline 2015_LAI_AGB_understory_clipping_TOS_Nakaji.csv & $\begin{array}{l}\text { AGB and LAI of understory observed using a clipping } \\
\text { method on August 20, } 2015 \text { at TOS site. }\end{array}$ \\
\hline 2018_LAI-2200_understory_TOS_Akitsu.csv & $\begin{array}{l}\text { LAI of understory obtained using the LAI- } 2200 \text { on } \\
\text { August 7, } 2018 \text { at TOS site. }\end{array}$ \\
\hline 2018_fAPAR_TOS_Akitsu.csv & fAPAR observed on August 7, 2018 at TOS site. \\
\hline 2005_2018_tree_census_FHK_Okano.csv & $\begin{array}{l}\text { Tree census data with tree location from } 2005 \text { to } 2018 \\
\text { at FHK site. }\end{array}$ \\
\hline 2018_AGB_FHK_Akitsu.csv & $\begin{array}{l}\text { AGB observed in } 2018 \text { at each observation zone at } \\
\text { FHK site. }\end{array}$ \\
\hline 2014_LAI-2000_canopy_FHK_Akitsu.csv & $\begin{array}{l}\text { LAI of canopy obtained using the LAI- } 2000 \text { on August } \\
28,2014 \text { at FHK site. }\end{array}$ \\
\hline 2015_LAI-2000_canopy_FHK_Akitsu.csv & $\begin{array}{l}\text { LAI of canopy obtained using the LAI-2000 on } \\
\text { September 21, } 2015 \text { at FHK site. }\end{array}$ \\
\hline 2018_LAI-2200_canopy_FHK_Akitsu.csv & $\begin{array}{l}\text { LAI of canopy obtained using the LAI- } 2200 \text { on August } \\
\text { 2, } 2018 \text { at FHK site. }\end{array}$ \\
\hline 2018_LAI-2200_understory_FHK_Akitsu.csv & $\begin{array}{l}\text { LAI of understory obtained using the LAI-2200 on } \\
\text { August 2, } 2018 \text { at FHK site. }\end{array}$ \\
\hline 2018_fAPAR_FHK_Akitsu.csv & fAPAR observed on August 2, 2018 at FHK site. \\
\hline 2018_2019_LAI_AGB_WTR_Akitsu.csv & LAI and AGB observed in 2018 and 2019 at WTR site. \\
\hline 2018_fAPAR_WTR_Akitsu.csv & fAPAR observed on June 6, 2018 at WTR site. \\
\hline 2018_LAI_AGB_MBN_Akitsu.csv & $\begin{array}{l}\text { AGB and LAI data observed on August } 23 \text { and 24, } \\
2018 \text { at MBN site. }\end{array}$ \\
\hline 2019_LAI_AGB_DGT_Akitsu.csv & $\begin{array}{l}\text { AGB and LAI data observed on August } 8 \text { and 9, } 2019 \\
\text { at DGT site. }\end{array}$ \\
\hline 2019_LAI_AGB_KYM_Akitsu.csv & $\begin{array}{l}\text { AGB and LAI data observed on August 13, } 2019 \text { at } \\
\text { KYN site. }\end{array}$ \\
\hline lat_lon_XXX.csv & $\begin{array}{l}\text { Latitude and longitude at each observation point at } \\
\text { XXX site, where XXX means the site name. }\end{array}$ \\
\hline 2015_2019_mean_AGB_all_sites.csv & $\begin{array}{l}\text { Mean and standard error of AGB in the } \\
500 \mathrm{~m} \times 500 \mathrm{~m} \text { area from } 2015 \text { to } 2019 \text { at all sites. }\end{array}$ \\
\hline 2014_2019_mean_LAI_all_sites.csv & $\begin{array}{l}\text { Mean and standard error of LAI in the } 500 \mathrm{~m} \times 500 \mathrm{~m} \\
\text { area from } 2014 \text { to } 2019 \text { at all sites. }\end{array}$ \\
\hline 2018_mean_fAPAR_all_sites.csv & $\begin{array}{l}\text { Mean and standard error of LAI in the } 500 \mathrm{~m} \times 500 \mathrm{~m} \\
\text { area in } 2018 \text { at all sites. }\end{array}$ \\
\hline
\end{tabular}

Abbreviations: AGB, above-ground biomass; fAPAR, fraction of absorbed photosynthetically active radiation; LAI, leaf area index. 
T A B L E 6 Description of columns in the 2017_tree_census_TOS_Nakaji.csv

\begin{tabular}{|c|c|c|}
\hline $\begin{array}{l}\text { Variable } \\
\text { name }\end{array}$ & Unit & Variable definition \\
\hline point_ID & - & $\begin{array}{l}\text { Observation point } \\
\text { identification (ID). }\end{array}$ \\
\hline tree_ID & - & Tree ID. \\
\hline species & - & Tree species name. \\
\hline DBH_2017 & $\mathrm{cm}$ & $\begin{array}{l}\text { DBH }(1.3 \mathrm{~m}) \text { measured } \\
\text { in November } 2017 .\end{array}$ \\
\hline height_2017 & $\mathrm{m}$ & $\begin{array}{l}\text { Estimated tree height using a } \\
\text { DBH measured } \\
\text { in November } 2017 .\end{array}$ \\
\hline gravity & $\mathrm{g} \mathrm{cm}^{-3}$ & Wood specific gravity $(\rho)$. \\
\hline AGB_2017 & $\mathrm{kg}$ & AGB for each tree. \\
\hline method & - & AGB estimation method. \\
\hline
\end{tabular}

Note: "NA" means not available. "grav_oven" means AGB was calculated using an oven-dried $\rho$, "grav_air" means AGB was calculated using an oven-dried $\rho$ estimated from air-dried $\rho$, "grav_other" means AGB was calculated using an oven-dried $\rho$ of the other species and "without_grav" means AGB was calculated using the equation without using $\rho$.

Abbreviations: AGB, above-ground biomass; $\mathrm{DBH}$, diameter at breast height.

TABLE 7 Description of columns in the 2017_AGB_TOS_Akitsu.csv

\begin{tabular}{lll} 
Variable name & Unit & Variable definition \\
\hline point_ID & - & $\begin{array}{c}\text { Observation point } \\
\text { identification. }\end{array}$ \\
& $\mathrm{Mg} \mathrm{ha}^{-1}$ & AGB observed in a \\
AGB_2017 & & $1,000-\mathrm{m}^{2}$ area in 2017. \\
\hline
\end{tabular}

Abbreviation: AGB, above-ground biomass.

Total fAPAR ( $f A P A R_{\text {total }}$; unitless) at each observation point was calculated by

$f A P A R_{\text {total }}=\frac{P A R_{\text {above }} \downarrow-P A R_{\text {above }} \uparrow-P A R_{\text {under }} \downarrow+P A R_{\text {under }} \uparrow}{P A R_{\text {above }} \downarrow}$.

At the WTR site, PAR above $\downarrow$ was observed using the Encased LI-190 fixed on a tripod stand on the embankment near the observation point. A reflectance of PAR from the canopy $\left(R_{\mathrm{PAR}}^{\text {canopy }}\right)$ was observed using two PAR02Ds mounted on a drone which has gimbals to keep the sensors level. It is because $\operatorname{PAR}_{\text {above }} \uparrow$ could not be observed on the ground due to the plant height which was $4 \mathrm{~m}$ or more and no observation tower at the WTR site. $\mathrm{PAR}_{\text {under }} \downarrow$ and $\mathrm{PAR}_{\text {under }} \uparrow$ were observed under the canopy using the LI-190R equipped with the LAI-2200C
T A B L E 8 Description of columns in the 2015_LAI2200_canopy_TOS_Akitsu.csv, 2016_LAI2200_canopy_TOS_Nakaji.csv, and 2019_LAI2200_canopy_TOS_Nakaji.csv

\begin{tabular}{|c|c|c|}
\hline $\begin{array}{l}\text { Variable } \\
\text { name }\end{array}$ & Unit & $\begin{array}{l}\text { Variable } \\
\text { definition }\end{array}$ \\
\hline point_ID & - & $\begin{array}{c}\text { Observation point } \\
\text { identification. }\end{array}$ \\
\hline YYYY_MMDD_PAI & $\mathrm{m}^{2} \mathrm{~m}^{-2}$ & $\begin{array}{l}\text { PAI observed } \\
\text { using LAI-2200 } \\
\text { on MM DD, } \\
\text { YYYY } \\
\text { (PAI leafless }) .\end{array}$ \\
\hline YYYY_MMDD_PAI & $\mathrm{m}^{2} \mathrm{~m}^{-2}$ & $\begin{array}{l}\text { PAI observed } \\
\text { using LAI-2200 } \\
\text { on MM DD, } \\
\text { YYYY } \\
\left(P A I_{\text {c_LAI-2200 }) .}\right.\end{array}$ \\
\hline $\begin{array}{l}\text { YYYY_MMDD_ } \\
\text { LAI_2200 }\end{array}$ & $\mathrm{m}^{2} \mathrm{~m}^{-2}$ & $\begin{array}{l}\text { LAI observed } \\
\text { using LAI-2200 } \\
\text { on } \\
\text { MM DD, YYYY } \\
\left(L A I_{\mathrm{c}-2200}\right) .\end{array}$ \\
\hline $\begin{array}{l}\text { YYYY_MMDD_ } \\
\text { LAI }\end{array}$ & $\mathrm{m}^{2} \mathrm{~m}^{-2}$ & $\begin{array}{l}\text { LAI calibrated } \\
\text { using a litter- } \\
\text { fall LAI on MM } \\
\text { DD, YYYY } \\
\left(L A I_{c}\right) .\end{array}$ \\
\hline
\end{tabular}

Note: "NA" means missing or anomalous value. YYYY means the year, MM means the month, DD means the day.

Abbreviations: LAI, leaf area index; PAI, plant area index.

in synchronization with the observation of $\mathrm{PAR}_{\text {above }} \downarrow$. $f A P A R_{\text {total }}$ was calculated at each observation point by

$$
f A P A R_{\text {canopy }}=1-R_{\mathrm{PAR}}^{\text {canopy }}+\frac{P A R_{\text {under }} \uparrow-P A R_{\text {under }} \downarrow}{P A R_{\text {above }} \downarrow},
$$

where $R_{\mathrm{PAR}}^{\text {canopy }}$ is 0.0566056 which was the mean observed using a drone at the WTR site.

(f) Location survey:

The location of the observation points was surveyed using the A-325 (Hemisphere GNSS Inc.) at the TOS site. At the FHK site, it was surveyed using the Trimble M5 $2^{\prime \prime}$ ST (Trimble Inc.) and the GPSmap 60CSx (Garmin Ltd.). At the MBN, DGT, and KYM sites, it was surveyed using the GPSmap 60CSx.

(g) Sample mean and standard error of the mean (SEM) within the $500 \mathrm{~m} \times 500 \mathrm{~m}$ area:

The sample means of LAI, AGB, and fAPAR were calculated by

$$
\bar{x}=\frac{\sum_{i=1}^{n} x_{i}}{n},
$$


T A B L E 9 Description of columns in the 2018_LAI-2200_canopy_TOS_Nakaji.csv

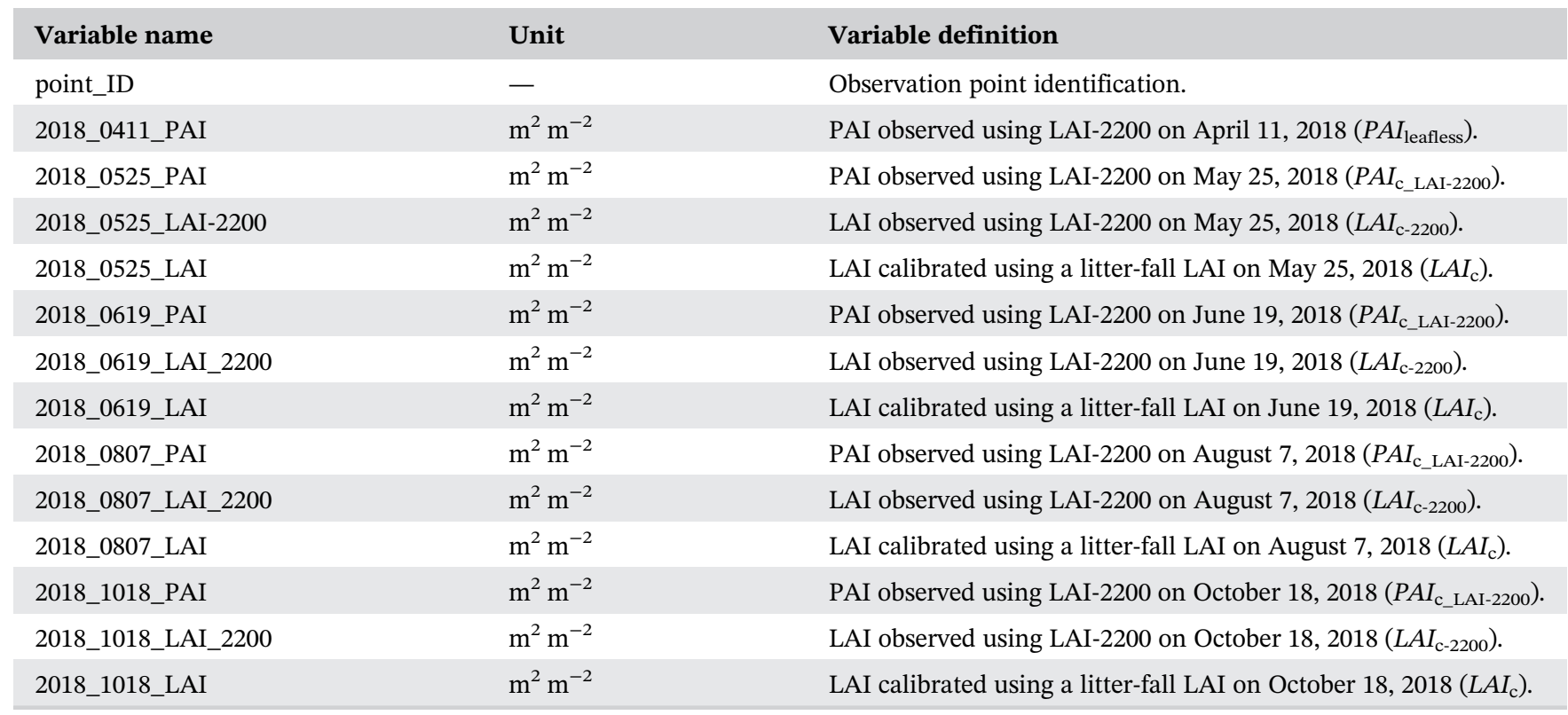

Note: "NA" means missing or anomalous value. For the 5E14 observation point, the value of 2017_0428_PAI was used instead of the anomalous value of 2018_0411_PAI.

Abbreviations: LAI, leaf area index; PAI, plant area index.

T A B L E 10 Description of columns in the 2018_LAI2200_understory_TOS_Akitsu.csv

\begin{tabular}{|lll|}
\hline Variable name & Unit & Variable definition \\
\hline point_ID & - & Observation point identification. \\
\hline 2018_0807_LAIu & $\mathrm{m}^{2} \mathrm{~m}^{-2}$ & $\begin{array}{c}\text { LAI observed using LAI-2200 } \\
\text { on August 7, 2018 }\left(L A I_{\mathrm{u}}\right) .\end{array}$ \\
\hline
\end{tabular}

Note: "NA" means missing or anomalous value.

Abbreviation: LAI, leaf area index.

where $\bar{x}$ is the sample mean, $x_{i}$ is each sample data and $n$ is the number of the sample. The SEM indicates how far the sample mean of the data may be from the true population mean. It was calculated as follows:

$$
\begin{gathered}
S E M=\frac{s}{\sqrt{n}}, \\
S=\sqrt{\frac{\sum_{i=1}^{n}\left(x_{i}-\bar{x}\right)^{2}}{n-1},}
\end{gathered}
$$

where $s$ is the standard deviation.

\section{7 | Data structure}

\subsection{1 | Data files}

The names of the data files are described in Table 5.
TABLE 11 Description of columns in the

\begin{tabular}{|c|c|c|}
\hline Variable name & Unit & Variable definition \\
\hline ID & - & $\begin{array}{l}\text { Observation group } \\
\text { identification. }\end{array}$ \\
\hline veg & - & Vegetation type. \\
\hline num & - & $\begin{array}{l}\text { Number of quadrats installed } \\
\text { at the observation point. }\end{array}$ \\
\hline LA & $\mathrm{cm}^{2}$ & $\begin{array}{l}\text { Area of clipped and measured } \\
\text { leaves. }\end{array}$ \\
\hline W_leaf1 & $\mathrm{g}$ & $\begin{array}{l}\text { Dry weight of clipped and } \\
\text { measured leaves. }\end{array}$ \\
\hline W_leaf2 & g & $\begin{array}{l}\text { Dry weight of leaves without } \\
\text { measuring leaves area. }\end{array}$ \\
\hline W_stem & $\mathrm{g}$ & $\begin{array}{l}\text { Dry weight of stems and the } \\
\text { others. }\end{array}$ \\
\hline LAI & $\mathrm{m}^{2} \mathrm{~m}^{-2}$ & LAI of understory. \\
\hline AGB & $\mathrm{Mg} \mathrm{ha}^{-1}$ & AGB. \\
\hline
\end{tabular}
2015_LAI_AGB_understory_clipping_TOS_Nakaji.csv

Abbreviations: AGB, above-ground biomass; LAI, leaf area index.

\subsection{2 | File format}

The data files are formatted in comma-separated values (csv) format with the UTF-8 encoding. 
TABLE 12 Description of columns in the 2018_fAPAR_TOS_Akitsu.csv

\begin{tabular}{|c|c|c|}
\hline Variable name & Unit & Variable definition \\
\hline point_ID & - & $\begin{array}{l}\text { Observation point } \\
\text { identification. }\end{array}$ \\
\hline $\begin{array}{l}\text { 2018_fAPAR_ } \\
\text { canopy }\end{array}$ & Unitless & $\begin{array}{l}\text { fAPAR of canopy } \\
\text { observed on August 7, } \\
\left.2018 \text { (fAPAR } R_{\text {canopy }}\right) \text {. }\end{array}$ \\
\hline $\begin{array}{l}\text { 2018_fAPAR_ } \\
\text { understory }\end{array}$ & Unitless & $\begin{array}{l}\text { fAPAR of understory } \\
\text { observed on August 7, } \\
2018\left(f A P A R_{\text {under }}\right) \text {. }\end{array}$ \\
\hline 2018_fAPAR_total & Unitless & $\begin{array}{l}\text { Total fAPAR observed } \\
\text { on August } 7,2018 \\
\left(f A P A R_{\text {total }}\right) .\end{array}$ \\
\hline
\end{tabular}

Abbreviation: fAPAR, fraction of absorbed photosynthetically active radiation.

\subsection{3 | Variable definitions}

(a) Tree census data including AGB for each tree at the TOS site:

The columns in the 2017_tree_census_TOS_Nakaji. csv include the following data (Table 6). The columns in the 2017_AGB_TOS_Akitsu.csv include the following data (Table 7).

(b) LAI data using LAI-2200 at the TOS site:

There are four files for canopy LAI: 2015_LAI2200_canopy_TOS_Akitsu.csv, 2016_LAI-2200_canopy_ TOS_Nakaji.csv, 2018_LAI-2200_canopy_TOS_Nakaji. csv, and 2019_LAI-2200_canopy_TOS_Nakaji.csv. Moreover, there is a file for understory LAI: 2018_LAI2200_understory_TOS_Akitsu.csv. The columns in the 2015_LAI-2200_canopy_TOS_Akitsu.csv, 2016_LAI-

T A B L E 13 Description of columns in the 2005_2018_tree_census_FHK_Okano.csv

\begin{tabular}{|c|c|c|}
\hline Variable name & Unit & Variable definition \\
\hline tree_ID & - & Tree identification. \\
\hline species & - & Tree species name. \\
\hline y_SN & $\mathrm{m}$ & Y coordinate from the southwest corner of the tree census area to the north. \\
\hline DBH_2005 & $\mathrm{cm}$ & DBH (1.2 m) measured in December 2005. \\
\hline DBH_2007 & $\mathrm{cm}$ & DBH (1.2 m) measured in December 2007. \\
\hline DBH_2008 & $\mathrm{cm}$ & DBH (1.2 m) measured in December 2008. \\
\hline DBH_2009 & $\mathrm{cm}$ & DBH (1.2 m) measured in December 2009. \\
\hline DBH_2010 & $\mathrm{cm}$ & DBH (1.2 m) measured in December 2010. \\
\hline DBH_2014 & $\mathrm{cm}$ & DBH (1.2 m) measured in December 2014. \\
\hline DBH_2015 & $\mathrm{cm}$ & DBH (1.2 m) measured in December 2015. \\
\hline DBH_2016 & $\mathrm{cm}$ & DBH (1.2 m) measured in December 2016. \\
\hline DBH_2017 & $\mathrm{cm}$ & DBH (1.2 m) measured in December 2017. \\
\hline DBH_2018 & $\mathrm{cm}$ & DBH (1.2 m) measured in December 2018. \\
\hline height_2005 & $\mathrm{m}$ & Tree height measured in December 2005. \\
\hline height_2007 & $\mathrm{m}$ & Tree height measured in December 2007. \\
\hline height_2009 & $\mathrm{m}$ & Tree height measured in December 2009. \\
\hline
\end{tabular}

Abbreviations: AGB, above-ground biomass; DBH, diameter at breast height; NA, not available. 
TA B L E 14 Description of columns in the 2018_AGB_FHK_Akitsu.csv

\begin{tabular}{lll} 
Variable name & Unit & Variable definition \\
\hline zone_ID & - & $\begin{array}{c}\text { Identification of } \\
\text { observation zone. }\end{array}$ \\
\hline AGB_2018 & $\mathrm{Mg} \mathrm{ha}^{-1}$ & AGB observed in a \\
& $100-\mathrm{m}^{2}$ area in 2018.
\end{tabular}

Abbreviation: AGB, above-ground biomass.

T A B L E 15 Description of columns in the 2014_LAI-

2000_canopy_FHK_Akitsu.csv, 2015_LAI-

2000_canopy_FHK_Akitsu.csv, and 2018_LAI-

2200_canopy_FHK_Akitsu.csv

\begin{tabular}{|lll} 
Variable name & Unit & Variable definition \\
\hline point_ID & - & Observation point identification. \\
YYYY_MMDD_ & $\mathrm{m}^{2} \mathrm{~m}^{-2}$ & LAI observed using \\
LAI_2200 & & LAI-2200/LAI-2000 on \\
& & MM DD, YYYY $\left(L A I_{\mathrm{c}-2200}\right)$. \\
YYYY_MMDD_ & $\mathrm{m}^{2} \mathrm{~m}^{-2}$ & LAI calibrated using a \\
LAI & & litter-fall LAI on MM \\
& & DD, YYYY $\left(L A I_{\mathrm{c}}\right)$.
\end{tabular}

Note: YYYY means the year, MM means the month, DD means the day.

Abbreviation: LAI, leaf area index.

2200_canopy_TOS_Nakaji.csv, and 2019_LAI2200_canopy_TOS_Nakaji.csv include the following data (Table 8). The columns in the 2018_LAI2200_canopy_TOS_Nakaji.csv include the following data (Table 9). The columns in the 2018_LAI-2200_understory_TOS_Akitsu.csv include the following data (Table 10).

(c) LAI and AGB data for understory vegetation using a clipping method at the TOS site:

The columns in the 2015_LAI_AGB_understory_ clipping_TOS_Nakaji.csv include the following data (Table 11).

(d) fAPAR data at the TOS site:

The columns in the 2018_fAPAR_TOS_Akitsu.csv include the following data (Table 12).

(e) Tree census data including AGB for each tree at the FHK site:

The columns in the 2005_2018_tree_census_FHK_ Okano.csv include the following data (Table 13). The columns in the 2018_AGB_FHK_Akitsu.csv include the following data (Table 14).

(f) LAI data at the FHK site:

There are four files for canopy LAI: 2014_LAI-2000_ canopy_FHK_Akitsu.csv, 2015_LAI-2000_canopy_FHK_ Akitsu.csv, and 2018_LAI-2200_canopy_FHK_Akitsu.csv.
T A B LE 16 Description of columns in the 2018_LAI2200_understory_FHK_Akitsu.csv

\begin{tabular}{lll}
\hline Variable name & Unit & Variable definition \\
\hline point_ID & - & $\begin{array}{c}\text { Observation point } \\
\text { identification. }\end{array}$ \\
& & LAI observed using LAI- \\
2018_0802_LAIu & $\mathrm{m}^{2} \mathrm{~m}^{-2}$ & 2200 on August 2, \\
& & $2018\left(L A I_{\mathrm{u}}\right)$. \\
\hline
\end{tabular}

Abbreviation: LAI, leaf area index.

T A B LE 17 Description of columns in the 2018_fAPAR_FHK_Akitsu.csv

\begin{tabular}{|c|c|c|}
\hline Variable name & Unit & Variable definition \\
\hline point_ID & - & $\begin{array}{l}\text { Observation point } \\
\text { identification. }\end{array}$ \\
\hline 2018_fAPAR_canopy & Unitless & $\begin{array}{l}\text { fAPAR of canopy } \\
\text { observed on August 2, } \\
2018\left(f A P A R_{\text {canopy }}\right) \text {. }\end{array}$ \\
\hline 2018_fAPAR_understory & Unitless & $\begin{array}{l}\text { fAPAR of understory } \\
\text { observed on August 2, } \\
2018\left(f A P A R_{\text {under }}\right) \text {. }\end{array}$ \\
\hline 2018_fAPAR_total & Unitless & $\begin{array}{l}\text { Total fAPAR observed } \\
\text { on August } 2,2018 \\
\left(f A P A R_{\text {total }}\right)\end{array}$ \\
\hline
\end{tabular}

Abbreviation: fAPAR, fraction of absorbed photosynthetically active radiation.

The columns in the files include the following data (Table 15). Moreover, there is a file for understory LAI: 2018_LAI-2200_understory_FHK_Akitsu.csv. The columns in the file include the following data (Table 16).

(g) fAPAR data at the FHK site:

The columns in the 2018_fAPAR_FHK_Akitsu.csv include the following data (Table 17).

(h) LAI and AGB data at the WTR site:

The columns in the 2018_2019_LAI_AGB_ WTR_Akitsu.csv include the following data (Table 18).

(i) fAPAR data at the WTR site:

The columns in the 2018_fAPAR_WTR_Akitsu.csv include the following data (Table 19).

(j) LAI and AGB data at Mongolian sites:

There are three files at Mongolian sites: 2018_LAI_ AGB_MBN_Akitsu.csv, 2019_LAI_AGB_DGT_Akitsu. csv, and 2019_LAI_AGB_KYM_Akitsu.csv.

The columns in the files include the following data (Table 20).

(k) Latitude and longitude at each observation point:

There are six files about latitude and longitude at each observation site: lat_lon_TOS.csv, lat_lon_FHK.csv, lat_lon_WTR.csv, lat_lon_MBN.csv, lat_lon_DGT.csv, 
TA B L E 18 Description of columns in the 2018_2019_LAI_AGB_WTR_Akitsu.csv

\begin{tabular}{|lll}
\hline Variable name & Unit & $\begin{array}{l}\text { Variable definition } \\
\text { point_ID }\end{array}$ \\
$\begin{array}{lll}\text { Observation point } \\
\text { identification. }\end{array}$ \\
\hline LAI_2018_0606 & $\mathrm{m}^{2} \mathrm{~m}^{-2}$ & LAI observed on June 6, 2018. \\
\hline AGB_2018_0606 & $\mathrm{Mg} \mathrm{ha}^{-1}$ & AGB observed on June 6, 2018. \\
\hline LAI_2018_0723 & $\mathrm{m}^{2} \mathrm{~m}^{-2}$ & $\begin{array}{c}\text { LAI observed on July 23 and } \\
\text { 24, 2018. }\end{array}$ \\
\hline AGB_2018_0723 & $\mathrm{Mg} \mathrm{ha}^{-1}$ & $\begin{array}{c}\text { AGB observed on July 23 and } \\
\text { 24, 2018. }\end{array}$ \\
\hline LAI_2019_0411 & $\mathrm{m}^{2} \mathrm{~m}^{-2}$ & $\begin{array}{c}\text { LAI observed on April 11, } \\
\text { 2019. }\end{array}$ \\
\hline AGB_2019_0411 & $\mathrm{Mg} \mathrm{ha}^{-1}$ & AGB observed on April 11, \\
& & 2019.
\end{tabular}

Abbreviations: AGB, above-ground biomass; LAI, leaf area index; NA, not available.

TABLE 19 Description of columns in the 2018_fAPAR_WTR_Akitsu.csv

\begin{tabular}{|c|c|c|}
\hline Variable name & Unit & Variable definition \\
\hline point_ID & - & $\begin{array}{l}\text { Observation point } \\
\text { identification. }\end{array}$ \\
\hline 2018_fAPAR_total & Unitless & $\begin{array}{l}\text { Total fAPAR observed } \\
\text { on June } 6,2018 \\
\left(f A P A R_{\text {canopy }}\right) .\end{array}$ \\
\hline
\end{tabular}

Abbreviation: fAPAR, fraction of absorbed photosynthetically active radiation.

TA B LE 20 Description of columns in the 2018_LAI_AGB_MBN_Akitsu.csv, 2019_LAI_AGB_DGT_Akitsu. csv and 2019_LAI_AGB_KYM_Akitsu.csv

\begin{tabular}{lll} 
Variable name & Unit & Variable definition \\
\hline point_ID & - & Observation point identification. \\
LAI & $\mathrm{m}^{2} \mathrm{~m}^{-2}$ & LAI. \\
\hline AGB & $\mathrm{Mg} \mathrm{ha}^{-1}$ & AGB. \\
\hline
\end{tabular}

Abbreviations: AGB, aboveground biomass; LAI, leaf area index.

and lat_lon_KYM.csv. The columns in the files include the following data (Table 21).

(1) The mean LAI and AGB in a $500 \mathrm{~m} \times 500 \mathrm{~m}$ area at each site:

There are three files: 2014_2019_mean_LAI_all_sites. csv, 2015_2019_mean_AGB_all_sites.csv, and 2018_mean_fAPAR_all_sites.csv. The columns in the 2014_2019_mean_LAI_all_sites.csv include the following data (Table 22). The columns in the 2015_2019_ mean_AGB_all_sites.csv include the following data (Table 23). The columns in the 2018_mean_APAR_all_sites include the following data (Table 24).
T A B L E 21 Description of columns in the lat_lon_TOS.csv, lat_lon_FHK.csv, lat_lon_WTR.csv, lat_lon_MBN.csv, lat_lon_DGT.csv, and lat_lon_KYM.csv

\begin{tabular}{lll}
\hline Variable name & Unit & Variable definition \\
\hline point_ID & - & $\begin{array}{c}\text { Observation point } \\
\text { identification. }\end{array}$ \\
\hline Latitude & $\begin{array}{c}\text { Degrees, minutes, } \\
\text { seconds }\end{array}$ & Latitude. \\
\hline Longitude & $\begin{array}{c}\text { Degrees, minutes, } \\
\text { seconds }\end{array}$ & Longitude. \\
\hline
\end{tabular}

TABLE 22 Description of columns in the 2014_2019_mean_LAI_all_sites.csv

\begin{tabular}{lll} 
Variable name & Unit & Variable definition \\
site & - & Observation site. \\
layer & - & Canopy or understory. \\
date & - & Observation date. \\
num & - & Number of observed points. \\
mean_LAI & $\mathrm{m}^{2} \mathrm{~m}^{-2}$ & Mean of LAI. \\
std & $\mathrm{m}^{2} \mathrm{~m}^{-2}$ & Standard deviation. \\
ste & $\mathrm{m}^{2} \mathrm{~m}^{-2}$ & Standard error of the mean. \\
\hline
\end{tabular}

Abbreviation: LAI, leaf area index.

TA B LE 23 Description of columns in the 2015_2019_mean_AGB_all_sites.csv

\begin{tabular}{lll} 
Variable name & Unit & Variable definition \\
site & - & Observation site. \\
layer & - & Canopy or understory. \\
date & - & Observation date. \\
num & - & Number of observed points. \\
mean_AGB & $\mathrm{Mg} \mathrm{ha}^{-1}$ & Mean of AGB. \\
std & $\mathrm{Mg} \mathrm{ha}^{-1}$ & Standard deviation. \\
ste & $\mathrm{Mg} \mathrm{ha}^{-1}$ & Standard error of the mean. \\
\hline
\end{tabular}

Abbreviation: AGB, above-ground biomass.

TA B L E 24 Description of columns in the 2018_mean_fAPAR_all_sites

\begin{tabular}{lll} 
Variable name & Unit & Variable definition \\
\hline site & - & Observation site. \\
layer & - & Canopy or understory. \\
date & - & Observation date. \\
num & - & Number of observed points. \\
mean_fAPAR & Unitless & Mean of fAPAR. \\
std & Unitless & Standard deviation. \\
ste & Unitless & Standard error of the mean. \\
\hline
\end{tabular}

Abbreviation: fAPAR, fraction of absorbed photosynthetically active radiation. 


\section{8 | Accessibility}

\subsection{1 | License}

This dataset is provided under a Creative Commons Attribution 4.0 International license (CC-BY 4.0) (https:// creativecommons.org/licenses/by/4.0/).

\subsection{2 | Location of storage}

http://db.cger.nies.go.jp/JaLTER/metacat/metacat/ERDP2020-16.1/jalter-en.

\section{ACKNOWLEDGMENTS}

This research was supported by a Global Change Observation Mission (GCOM: PI\#116, \#ER2GCF103) of the Japan Aerospace Exploration Agency (JAXA). The authors appreciate Tochigi City and Tonegawa River Upper Stream Office, Kanto Regional Development Bureau, Ministry of Land, Infrastructure, Transport and Tourism (MLIT), Japan for giving us the opportunity to observe LAI and AGB at the WTR site. Furthermore, the authors also thank a lot of students and researchers from the University of Tsukuba, Chiba University, Shinshu University, Hokkaido University, Japan Agency for Marine-Earth Science and Technology (JAMSTEC) and Japan Aerospace Exploration Agency (JAXA) who participate in our observations.

\section{ORCID}

Tomoko Kawaguchi Akitsu (10) https://orcid.org/0000-00017401-0621

Tatsuro Nakaji (1) https://orcid.org/0000-0002-3161-1539 Kenlo Nishida Nasahara (D) https://orcid.org/0000-00032646-6805

\section{REFERENCES}

Akitsu, T., Nasahara, K., Hideki, K., Saigusa, N., Hayashi, M., Nakaji, T., ... Honda, Y. (2015). JAXA super sites 500: Largescale ecological monitoring sites for satellite validation in Japan. In 2015 IEEE International Geoscience and Remote Sensing Symposium (IGARSS) (Vol. 2015, pp. 3866-3869). Milan, Italy: IEEE. https://doi.org/10.1109/IGARSS.2015.7326668

Akitsu, T., Nasahara, K., Nakaji, T., Hajime, K., Okano, T., Saigusa, N., ... Kobayashi, T. (2019, 2019). Validating GCOM-C terrestrial ecology products: How should in-situ observation be performed at satellite scale? In IGARSS 2019-2019 IEEE International Geoscience and Remote Sensing Symposium (pp. 9196-9199). Yokohama, Japan: IEEE. https://doi.org/10.1109/IGARSS.2019.8897899

Akitsu, T., Nasahara, K. N., Hirose, Y., Ijima, O., \& Kume, A. (2017). Quantum sensors for accurate and stable long-term photosynthetically active radiation observations. Agricultural and Forest Meteorology, 237, 171-183. https://doi.org/10.1016/j.agrformet.2017.01.011

Akitsu, T. K., Nakaji, T., Yoshida, T., Sakai, R., Mamiya, W., Terigele, Takagi, K., Honda, Y., Kajiwara, K., \&
Nasahara, K. N. (2020). Field data for satellite validation and forest structure modeling in a pure and sparse forest of Picea glehnii in northern Hokkaido. Ecological Research, 2020, 1-15. https://doi.org/10.1111/1440-1703.12114

Cohen, W. B., Maiersperger, T. K., Turner, D. P., Ritts, W. D., Pflugmacher, D., Kennedy, R. E., ... Gower, S. T. (2006). MODIS land cover and LAI collection 4 product quality across nine sites in the western hemisphere. IEEE Transactions on Geoscience and Remote Sensing, 44, 1843-1857. https://doi.org/10.1109/ TGRS.2006.876026

Fuster, B., Sánchez-Zapero, J., Camacho, F., García-Santos, V., Verger, A., Lacaze, R., ... Smets, B. (2020). Quality assessment of PROBA-V LAI, fAPAR and fCOVER collection $300 \mathrm{~m}$ products of copernicus global land service. Remote Sensing, 12. https://doi.org/10.3390/rs12061017

Ishihara, M., Utsugi, H., Tanouchi, H., Aiba, M., Kurokawa, H., Onoda, Y., ... Hiura, T. (2015). Efficacy of generic allometric equations for estimating biomass: A test in Japanese natural forests. Ecological Applications, 25, 1433-1446.

Ishihara, M. I., \& Hiura, T. (2011). Modeling leaf area index from litter collection and tree data in a deciduous broadleaf forest. Agricultural and Forest Meteorology, 151, 1016-1022.

Jonckheere, I., Fleck, S., Nackaerts, K., Muys, B., Coppin, P., Weiss, M., \& Baret, F. (2004). Review of methods for in situ leaf area index determination part I. Theories, sensors and hemispherical photography. Agricultural and Forest Meteorology, 121, 19-35. https://doi.org/10.1016/j.agrformet.2003.08.027

Kishima, T., Okamoto, S., \& Hayashi, S. (1962). Atlas of wood in color (in Japanese). Osaka, Japan: Hoikusha Publishers.

Morisette, J. T., Baret, F., Privette, J. L., Myneni, R. B., Nickeson, J., Garrigues, S., ... Cook, R. (2006). Validation of global moderateresolution LAI products: A framework proposed within the CEOS land product validation subgroup. IEEE Transactions on Geoscience and Remote Sensing, 44, 1-14.

Ogawa, F. (1969). Trial of forest type classification in relation to tree height and breast height diameter. (in Japanese) 1968 report JIBP-PT-F, 3-17.

Sellers, P., Hall, F., Ranson, K. J., Margolis, H., Kelly, B., Baldocchi, D., \& Crill, P. (1995). The Boreal EcosystemAtmosphere Study (BOREAS): An overview and early results from the 1994 field year. The Bulletin of the American Meteorological Society, 76, 1549-1577.

Sprugel, D. (1983). Correcting for bias in log-transformed allometric equations. Ecology, 64, 209-210.

Wang, Y., Woodcock, C. E., Buermann, W., Stenberg, P., Voipio, P., Smolander, H., ... Myneni, R. B. (2004). Evaluation of the MODIS LAI algorithm at a coniferous forest site in Finland. Remote Sensing of Environment, 91, 114-127. https://doi.org/10.1016/j.rse.2004. 02.007

How to cite this article: Akitsu TK, Nakaji T, Kobayashi H, et al. Large-scale ecological field data for satellite validation in deciduous forests and grasslands. Ecological Research. 2020;35:1009-1028. https://doi.org/10.1111/1440-1703.12155 